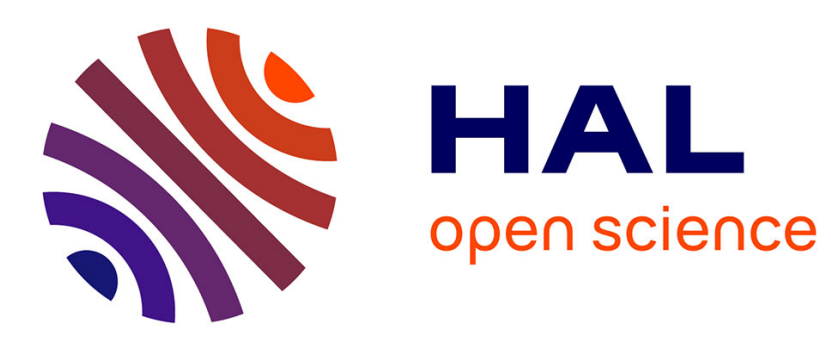

\title{
Damage Evaluation in Woven Glass Reinforced Polyamide 6.6/6 Composites Using Ultrasound Phase-Shift Analysis and X-ray Tomography
}

Pascal Pomarede, Fodil Meraghni, Laurent Peltier, Stéphane Delalande, Nico F. Declercq

\section{To cite this version:}

Pascal Pomarede, Fodil Meraghni, Laurent Peltier, Stéphane Delalande, Nico F. Declercq. Damage Evaluation in Woven Glass Reinforced Polyamide 6.6/6 Composites Using Ultrasound PhaseShift Analysis and X-ray Tomography. Journal of Nondestructive Evaluation, 2018, 37 (1), pp.12. 10.1007/s10921-018-0467-3 . hal-01761764

\section{HAL Id: hal-01761764 \\ https://hal.science/hal-01761764}

Submitted on 9 Apr 2018

HAL is a multi-disciplinary open access archive for the deposit and dissemination of scientific research documents, whether they are published or not. The documents may come from teaching and research institutions in France or abroad, or from public or private research centers.
L'archive ouverte pluridisciplinaire HAL, est destinée au dépôt et à la diffusion de documents scientifiques de niveau recherche, publiés ou non, émanant des établissements d'enseignement et de recherche français ou étrangers, des laboratoires publics ou privés. 


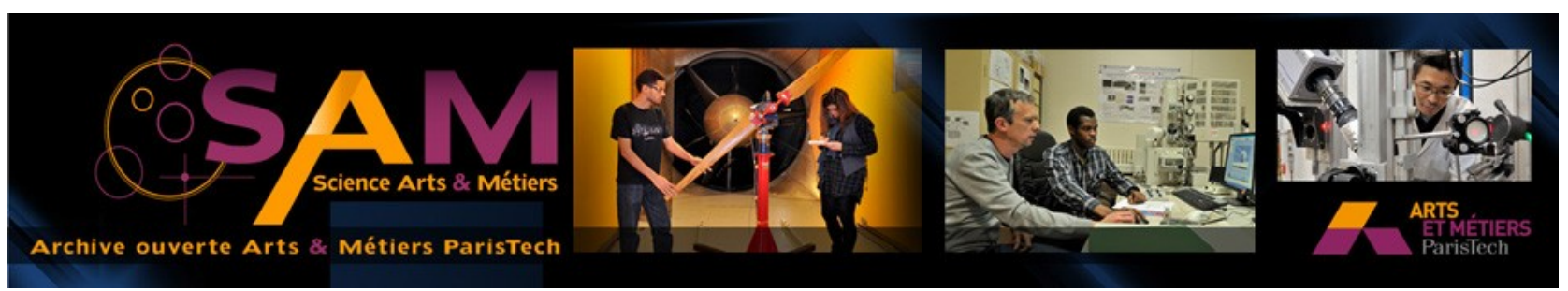

\section{Science Arts \& Métiers (SAM)}

is an open access repository that collects the work of Arts et Métiers ParisTech researchers and makes it freely available over the web where possible.

This is an author-deposited version published in: http://sam.ensam.eu

Handle ID: .http://hdl.handle.net/null

\section{To cite this version :}

Pascal POMAREDE, Fodil MERAGHNI, Laurent PELTIER, Stephane DELALANDE, Nico F. DECLERCQ - Damage Evaluation in Woven Glass Reinforced Polyamide 6.6/6 Composites Using Ultrasound Phase-Shift Analysis and X-ray Tomography - Journal of Nondestructive Evaluation - Vol. 37, p.12 - 2018 


\title{
Damage Evaluation in Woven Glass Reinforced Polyamide 6.6/6 CompositesUsing UltrasoundPhase-ShiftAnalysisandX-ray Tomography
}

\author{
Pascal Pomarède ${ }^{1,2} \cdot$ Fodil Meraghni $^{1} \cdot$ Laurent Peltier $^{1} \cdot$ Stéphane Delalande $^{3} \cdot$ Nico F. Declercq $^{2,4}$
}

\begin{abstract}
The paper proposes a new experimental methodology, based on ultrasonic measurements, that aims at evaluating the anisotropic damage in woven semi-crystalline polymer composites through new damage indicators. Due to their microstructure, woven composite materials are characterized by an anisotropic evolution of damage induced by different damage mechanisms occurring at the micro or mesoscopic scales. In this work, these damage modes in polyamide 6.6/6-woven glass fiber reinforced composites have been investigated qualitatively and quantitatively by X-ray micro-computed tomography (mCT) analysis on composite samples cut according to two orientations with respect to the mold flow direction. Composite samples are initially damaged at different levels during preliminary interrupted tensile tests. Ultrasonic investigations using C-scan imaging have been carried out without yielding significant results. Consequently, an ultrasonic method for stiffness constants estimation based on the bulk and guided wave velocity measurements is applied. Two damage indicators are then proposed. The first consists in calculating the Frobenius norm of the obtained stiffness matrix. The second is computed using the phase shift between two ultrasonic signals respectively measured on the tested samples and an undamaged reference sample. Both X-ray mCT and ultrasonic investigations show a higher damage evolution with respect to the applied stress for the samples oriented at $45^{\circ}$ from the warp direction compared to the samples in the $0^{\circ}$ configuration. The evolution of the second ultrasonic damage indicator exhibits a good correlation with the void volume fraction evolution estimated by MCT as well as with the damage calculated using the measured elastic modulus reduction. The merit of this research is of importance for the automotive industry.
\end{abstract}

Keywords Composite materials · Ultrasonics $\cdot \mathrm{X}$-ray tomography $\cdot$ Damage Indicator

\section{Introduction}

Woven reinforced thermoplastic composite materials are gaining interest in automotive applications [1-3], due to their important weight reduction in comparison with applications using metals. In addition, compared to a unidirectional rein- forcement, a woven fabric allows a better equilibrium and uniformity of the mechanical properties. Furthermore, they also have a better ability to withstand buckling and impact [4]. The latter characteristic is of critical interest for the automotive industry [5]; indeed it is essential to ensure a maximal resistance of structural parts, in the case of impact in particular for the driver's safety. To assess the in-service strength of an automotive component made of woven fabric composite that is subjected to damage accumulation, the development of an efficient methodology evaluating the damage is mandatory. This assessment should guide decisions to replace, to repair or to keep a composite component based on its damage tolerance. Non-destructive methods based on ultrasonic investigation naturally emerge as promising damage evaluation techniques thanks to their practicality, efficiency, diversity and their applicability on composite parts in-service. Nevertheless, ultrasonic techniques require 
appropriate signal processing to extract damage indicators that permit estimation of the residual stiffness, which is related to the component integrity.

In order to nondestructively assess all the elastic constants of a material, Markham [6] has studied a method based on ultrasonic measurements in immersion of bulk wave velocities and the use of the well-known Christoffel equation. He applied the method on an undamaged transversely isotropic composite material to determine the stiffness components. The method was then successfully used to measure the stiffness reduction of composites submitted to different levels of impact $[7,8]$ and tensile tests $[9,10]$. One of the advantages of this method is that the tested material is investigated in all directions (i.e. sample orientations) and therefore can provide all the components of the stiffness tensor and accordingly a complete anisotropic damage evaluation of the tested sample. This method was also extended for use with guided waves in several studies because of their established advantages [11,12]. In the industry one normally do not require full understanding of all physical phenomena involved but rather seek practical and workable techniques that are reliable. To our knowledge, no damage indicator, with simple interpretation, useful in the industry, for the global damage state, has been reported in the literature. Such task is carried out here, where an experimental methodology is developed for identifying proper damage indicators.

An alternative method, somewhat similar to the method proposed by Markham, is the polar-scan method [13,14]. As indicated by its name, a specific point of a sample is scanned for all accessible angles of incidence. For each polar angle, the signal amplitude is recorded and represented in a polar plot. Information such as damage level, stiffness, fiber misalignment, etc can be extracted from this polar figure. However, this technique requires a more complex apparatus than the one proposed by Markham because of the unavoidable double angular rotations. This limits therefore its application on site (in-service). Due to this limitation, the present approach measures the elastic constants using the ultrasonic method based on wave velocities measurement and described in the preceding paragraph. The aim of this study is then to propose an ultrasonic methodology to detect and to quantify damage growth, even when the cracks that propagate inside the sample cannot be detected by classical ultrasonic imaging techniques. As mentioned, this method could provide the whole stiffness tensor of a sample. However, it is more interesting to obtain a sole value to efficiently transcribe the global damage state of a tested sample. Two different experimental damage indicators are proposed for this purpose: The first is the norm of the stiffness tensor and the second is the phase angle shift between wave signals propagated through a damaged and an undamaged sample. It is worth noting that the time required to analyze the exper- imental results in order to obtain the first indicator can be quite long.

The woven reinforced composite material exhibits a specific damage scheme that is highly dependent on both the loading direction and the fiber orientation $[15,16]$. In this work, the damage characterization and evolution was performed on samples made of co-polyamide 6.6/6 based composites reinforced with woven glass fibers and submitted to tension tests interrupted at different stress levels. Two configurations of material samples were tested: (i) samples oriented at $0^{\circ}$ with respect to the warp direction and (ii) samples oriented at $45^{\circ}$ from the warp direction corresponding to the mold flow direction. A first damage estimation for the two samples configurations was carried out using the elastic modulus reduction. Various nondestructive tests were performed on the samples after loading, such as ultrasonic Cscan imaging that was not able to capture the damage zone in all tested samples. To address this aspect, the damage mechanisms induced by the different tensile tests were investigated by X-ray micro-computed tomography (mCT). This provided a qualitative description of the main damage mechanisms and the quantitative estimation of void volume fraction evolution. The latter was compared to the damage indicators evolution obtained with the ultrasonic technique.

The paper is organized as follows: in Sect. 2 the investigated composite material and the tensile tests procedure are presented. Ultrasonic C-scan imaging results obtained on samples after interrupted tensile tests are presented and discussed. X-ray mCT investigation procedure and results, on samples in both $0^{\circ}$ and $45^{\circ}$ configurations are discussed in Sect. 3. Ultrasonic analysis and the estimation of the damage evolution are presented in the 4th section. The evolution of the stiffness components function of the applied stress level is also discussed for both $0^{\circ}$ and $45^{\circ}$ samples. In Sect. 5 , the two proposed damage indicators are calculated using the ultrasonic results from the previous section. Both ultrasonic damaged indicators are compared with the estimation of damage calculated using the elastic modulus reduction (presented in Sect. 2) and with the void volume fraction evolution (discussed in Sect. 3) leading to concluding remarks.

\section{Material Description and Preliminary Tests}

\subsection{Material}

The composite material considered for this study is referenced as VizilonTM SB63G1-T1.5-S3 and is manufactured by DuPont. The studied composite is produced by a thermocompression molding process and it consists of a 2/2 twill weave glass fabric reinforced co-polyamide 6.6/6, with three plies, of $1.53 \mathrm{~mm}$ thick in total. The overall 3D woven fabric of the studied composite material is shown in Fig. 1. The 


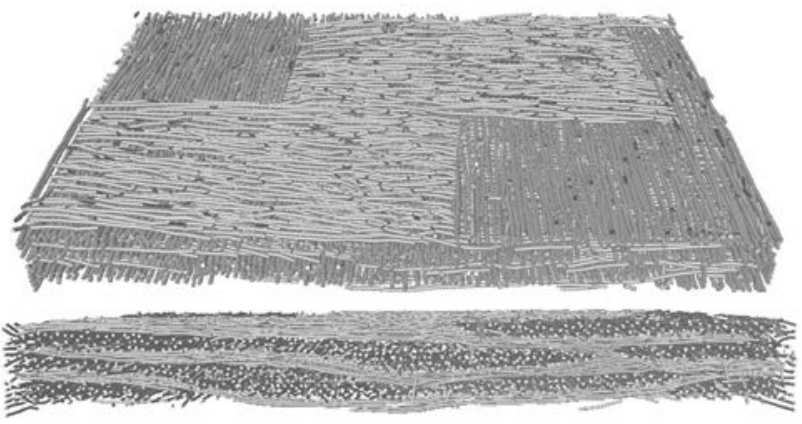

Fig. 1 Overall 3D mesostructure of the studied composite consisting of $2 / 2$ twill weave fabric reinforced polyamide $6.6 / 6$ matrix

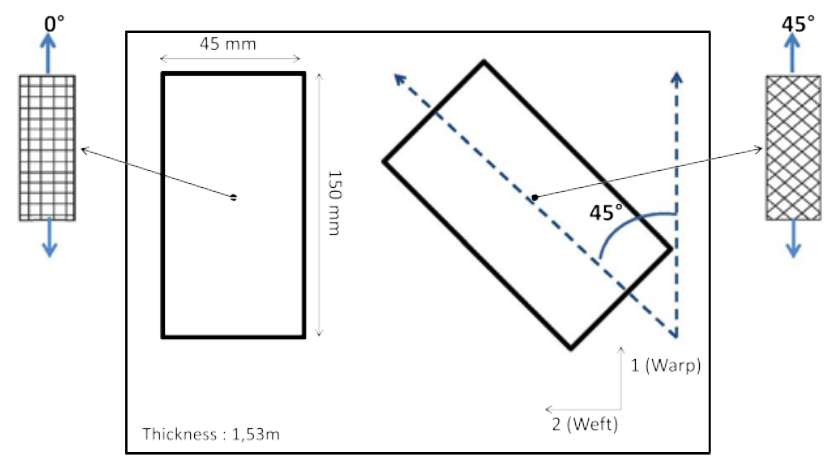

Fig. 2 Position of the samples oriented at $0^{\circ}$ and $45^{\circ}$ with respect to the warp direction assumed as the mold flow direction of the composite plate

weight fiber content is $63 \%$ corresponding to a fiber volume fraction of $43 \%$. Ten samples are cut in rectangular plate of $45 \mathrm{~mm}$ length and $150 \mathrm{~mm}$ width. Four samples are cut at $45^{\circ}$ with respect to the warp direction (mold flow direction) and six other ones are cut along the warp direction. The orientations of these two sets of samples are indicated in Fig.
2. The two different microstructures can be observed in the Fig. 3. All the samples are stored in a humidity chamber in order to have the same initial conditions in terms of relative humidity. The latter is set at a level of $50 \%$ for all tested composite material. Initial tensile tests are performed on the material until failure for both $0^{\circ}$ and $45^{\circ}$ sample configurations. The experimental stress/strain curves are normalized with respect of the tensile ultimate strength of the $0^{\circ}$ sample configuration.

\subsection{Tensile Tests Procedure}

The tested samples are subjected to an interrupted tensile loading at different levels. For $45^{\circ}$ samples configuration, the tensile tests are interrupted at the following stress levels: $0,30.5,61.1$, and $91.6 \%$ of $\boldsymbol{\sigma}_{U T S 45}{ }^{\circ}$, whereas for $0{ }^{\circ}$ configuration, the interruption occurs at the levels of $0,30.8,46.3$, $61.7,77.2$, and $92.6 \%$ of $\boldsymbol{\sigma}_{U_{T S O}}{ }^{\circ}$. The chosen loading values are schematically illustrated by means of red circles on the representative stress/strain curves in Fig. 4. All the tensile tests presented in this paper follow the same procedure.

To estimate the modulus reduction caused by these interrupted tensile tests, the samples are loaded to the prefixed stress values and then are unloaded (elastic release) back to zero force. The evolution of damage was computed as:

$D=1-\begin{aligned} & E_{n} \\ & E_{0}\end{aligned}$

Where $\mathrm{E}_{0}$ is the elastic modulus of the tested sample during the first loading and $E_{n}$ represents the Young's modulus of the tested sample during the elastic release. The $\mathrm{E}_{0}$ is estimated for every single sample between $0.2 \%$ and $0.4 \%$ of strain according to the standard ISO 527 . The $\mathrm{E}_{\mathrm{n}}$ values are cal-
Fig. 3 Cross-sectional observation with optical microscope of the $2 / 2$ twill weave fabric reinforced polyamide composite microstructure for samples oriented at $0^{\circ}$ and $45^{\circ}$. a $0^{\circ}$ sample, $\mathbf{b} 45^{\circ}$ sample and $\mathbf{c}$ Zoom-in on a sample's yarns in the $0^{\circ}$ orientation
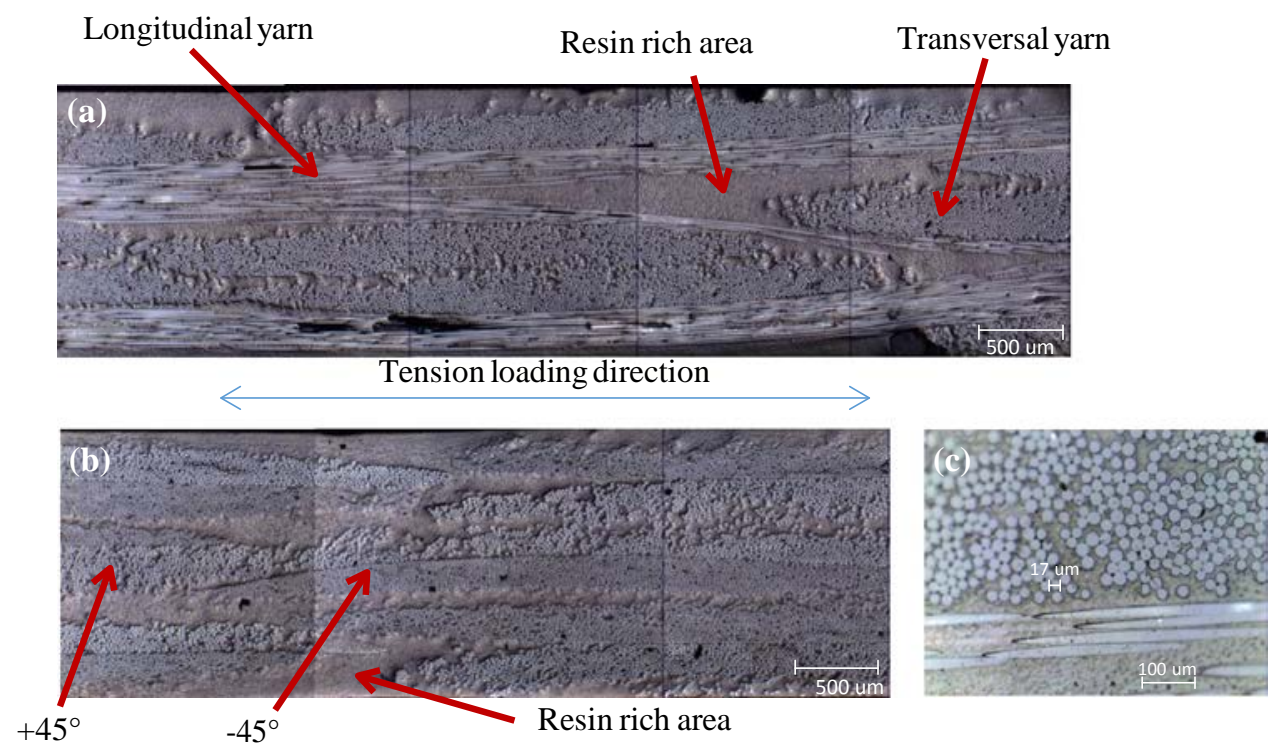


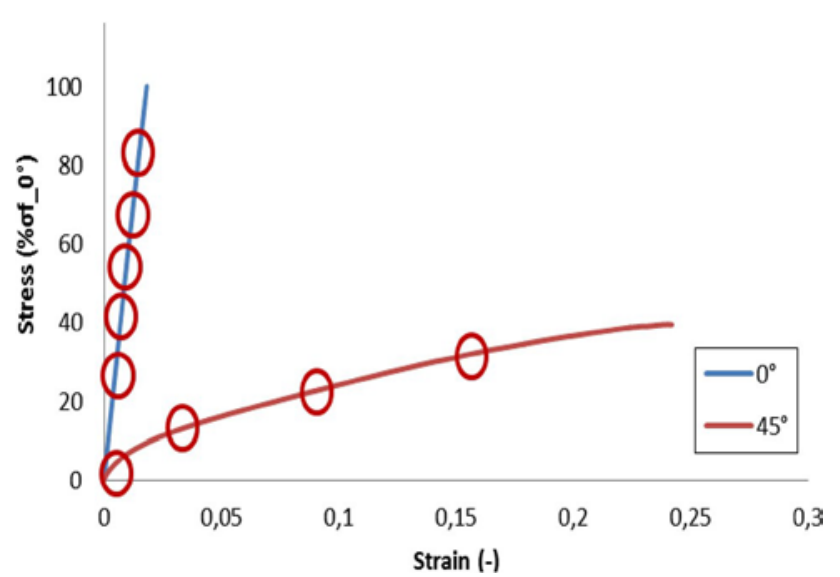

Fig. 4 Typical stress/strain responses of the $2 / 2$ twill weave fabric reinforced polyamide composite under tension at $0^{\circ}$ and $45^{\circ}$. The red circles show schematicaly where the tensile tests have been interupted for both tested configurations

culated after the unloading according to a common damage measurement procedure [17]. A representation of the elastic moduli calculation is depicted in Fig. 5a, b for the two tested sample configurations.

The samples are all loaded in tension at room temperature and at a constant strain rate of $10^{-4} \mathrm{~s}^{-1}$ to avoid the influence of viscosity. Tensile tests are performed in compliance with the standard ISO 5893 on a machine Z050 designed by Zwick Roell. The strains are measured using a "clip-on" extensometer manufactured by Epsilon Technology Corp.

As shown in Fig. 5, a noticeable difference is observed between the overall stress-strain responses of the two configuration samples, namely $0^{\circ}$ and $45^{\circ}$. In fact, for the samples tested at $0^{\circ}$, the behavior in tension is mostly linear and brittle since it is governed by the fiber breakage whereas the behav-

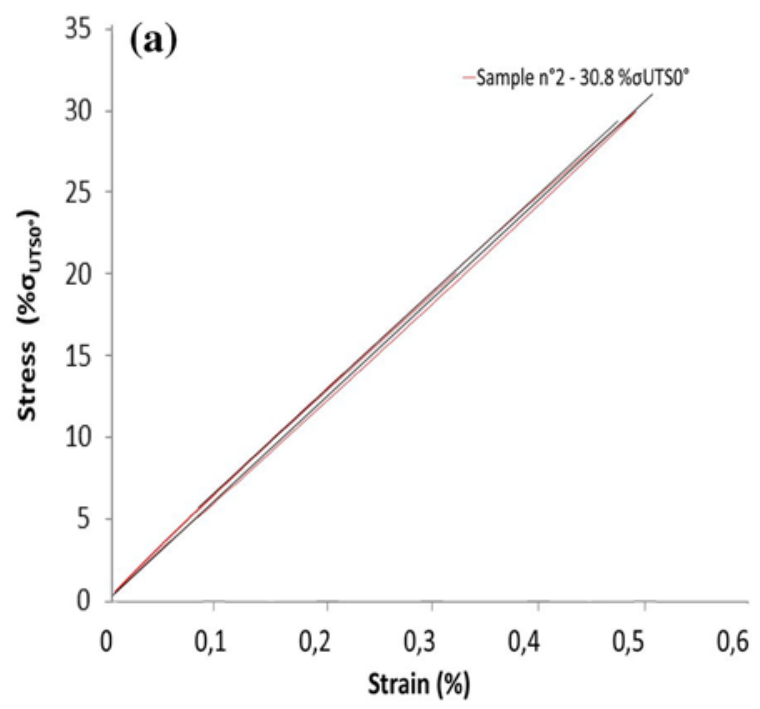

ior of the samples tested at $45^{\circ}$ exhibits a nonlinear ductile response mostly governed by the matrix rheology.

This is particularly clear for the evolution of the damage estimated on the elastic modulus reduction when the applied stress increases, as illustrated in Fig. 6. For the samples oriented at $45^{\circ}$ from the warp direction, the damage $D$ reaches a value of 0.53 close to the final failure. However, for the $0^{\circ}$ case, it only goes up to 0.1 . The values of damage for every tested sample are summarized in Table 1 . This damage estimation is employed as a first reference to validate the proposed ultrasonic damage indicators detailed in further sections. Indeed, as discussed, Fig. 6 indicates a higher amount of damage induce by the loading for the $45^{\circ}$ configuration, which could imply different damage mechanisms with different associated typical scales. In fact, to investigate the sensitivity of the ultrasonic techniques, it is necessary to consider different scales of induced damage. Hence, the typical scale of those mechanisms for the two sample configuration requires further study.

\subsection{Ultrasonic C-Scan in Transmission}

Ultrasonic imaging was performed on all tested samples to investigate the overall damage state of the samples cut at $0^{\circ}$ and $45^{\circ}$. Classical ultrasonic 2D C-scans in transmission were performed using a $5 \mathrm{MHz}$ frequency transducer, the maximal amplitude of the ultrasonic signal is measured and recorded at each point of the scanned area with a spatial resolution of $0.5 \mathrm{~mm}$. It is then plotted on Fig. 7 for both considered sample configurations. It is worth noting, that the values reported in Fig. 7 are the actual values of the ultrasound amplitude's signal without any averaging process on the scanned area of the tested specimen. As illustrated in Fig.

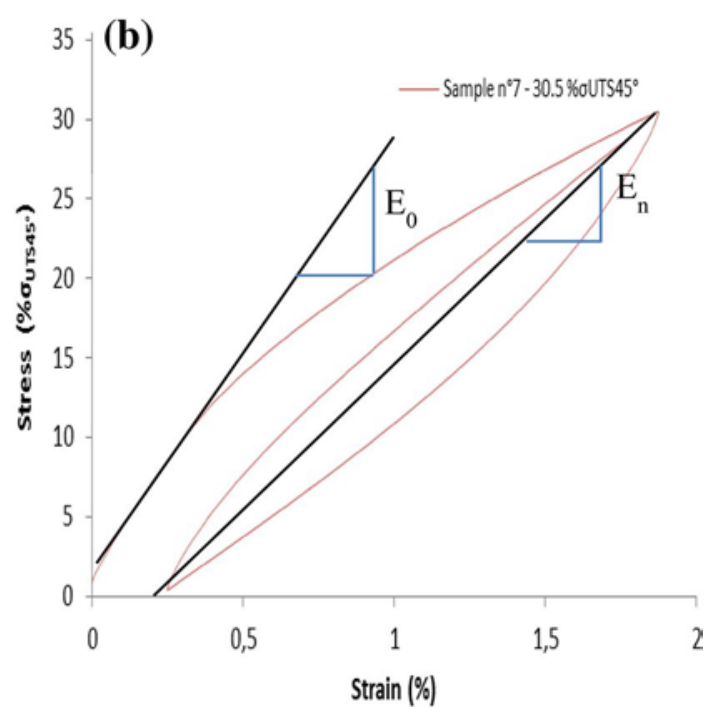

Fig. 5 Schematic represenation of the elastic moduli estimation of the of $E_{0}$ and $E_{n}$ for rerspectively a $0^{\circ}$ and $\mathbf{b} 45^{\circ}$ configuration samples 


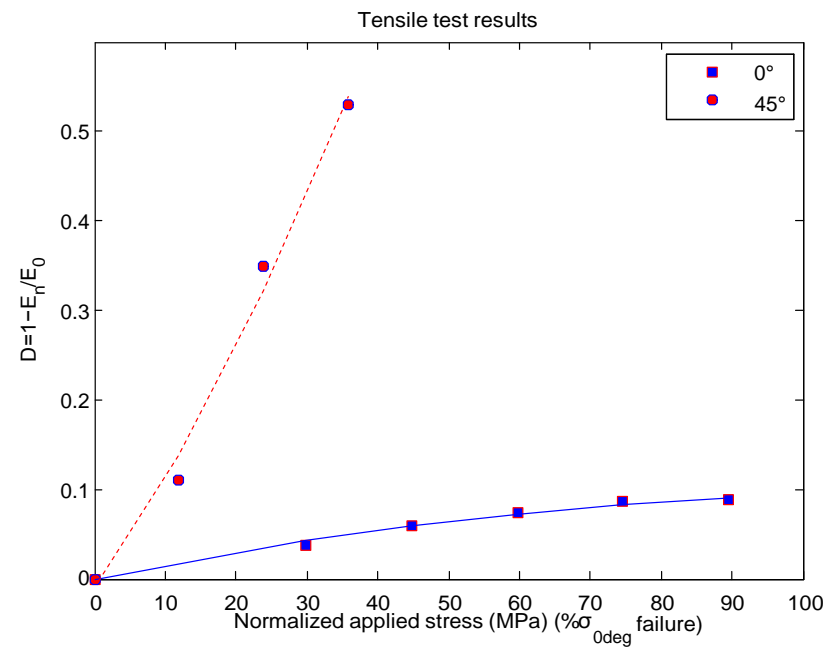

Fig. 6 Evolution of the the damage for $0^{\circ}$ and $45^{\circ}$ sample's configurations. The damage is estimated from the Young's modulus reduction for different applied stress levels

7a related to the samples tested at $0{ }^{\circ}$ from the warp direction, the attenuation of the ultrasound amplitude's signal remains low and a very slight difference, if any, was noticed when increasing the applied stress level from 0 to $92.6 \% \boldsymbol{\sigma}_{\text {UTS }}{ }^{\circ}$.

For the sample in $45^{\circ}$, the Fig. $7 \mathrm{~b}$ shows the evolution of amplitude attenuation (C-scan images) between the unloaded state and the ultimate state level prior failure $\left(92.6 \% \boldsymbol{\sigma}_{\boldsymbol{U}} \mathrm{TS}^{4} 5^{\circ}\right)$. Two damage zones were actually observed macroscopically and the related high attenuations in the signals were associated to the fibers buckling and the local delamination. In addition, the low signal attenuations observed at the border of the samples were clearly induced by a well-known border effect and were not caused by the mechanically induced damage.

As a partial result, one can conclude that the classical ultrasonic C-scan imaging, as applied in this study, suitably aimed at detecting the macroscopic damage in tested composite samples. It appears as a method which is neither reliable nor accurate for the detection of microscopic damage and the related stiffness reduction in the samples.

Note that other detection techniques based on spectrum analysis in the nonlinear ultrasonic domain could be applied for the detection of early damage with more sensitivity and spatial resolution. Among them, one can mention those using vibro-acoustic modulation $[18,19]$ or using higher harmonics [20,21].

scopic scale are investigated using X-ray micro-computed tomography (mCT). The damage characterization at this scale provides a quantitative estimation of void volume fraction evolution, which is related to the Young's modulus reduction.

\section{Damage Investigation Using X-ray Micro Computed Tomography}

\subsection{Experimental Procedure}

The X-ray micro-computed tomography (mCT) investigation and acquisitions were carried-out with an EasyTom (Nano) from $R X$ solutions. The general principle of $\mathrm{mCT}$ is detailed in the Fig. 8. The acquisition parameters were chosen in order to analyze a representative volume element (RVE) of the composite material. A resolution of 5.5-micrometer $(\mu \mathrm{m})$ voxel has been adopted for the acquisitions. With this resolution, material volumes of $16.5 \times 16.5 \times 1.5 \mathrm{~mm}$ were reconstructed after the acquisition. The analyzed areas on the samples were close to the middle of the sample, where the extensometer was clipped-on during the tensile tests. All the information about the selected parameters is summarized in Table 2. The sample was positioned on a rotating table while X-rays pass through to a flat panel detector. Images were recorded as grey level maps, for all rotation angles, on a computer, before a $3 \mathrm{D}$ reconstruction with the X-Act software

Table 1 Samples with their defined tensile loading for $0^{\circ}$ and $45^{\circ}$ samples configuration as well as their tensile induced damage

\begin{tabular}{|c|c|c|c|c|c|c|c|c|}
\hline Sample & 1 & 2 & & 3 & & 4 & 5 & 6 \\
\hline Configuration & $0^{\circ}$ & $0^{\circ}$ & & $0^{\circ}$ & & $0^{\circ}$ & $0^{\circ}$ & $0^{\circ}$ \\
\hline Definedloading & $0 \% \boldsymbol{\sigma}_{\text {UTSO }}^{\circ}$ & $30.8 \% \boldsymbol{\sigma}$ & UTSO & $46.3 \% \sigma$ & UTSO & $61.7 \% \boldsymbol{\sigma} \quad$ UTS0 & $77.2 \% \sigma \quad$ UTSO & $92.6 \% \sigma \quad{ }_{U T \varsigma} 0$ \\
\hline Strain & 0 & 0.005 & & 0.007 & & 0.010 & 0.013 & 0.016 \\
\hline Damage & 0 & 0.038 & & 0.061 & & 0.074 & 0.086 & 0.089 \\
\hline Sample & 7 & & 8 & & 9 & & 10 & \\
\hline Configuration & $5^{\circ}$ & & $45^{\circ}$ & & $45^{\circ}$ & & $45^{\circ}$ & \\
\hline Defined loading & $0 \% \sigma_{\text {UTS } 45}^{\circ}$ & & $30.5 \% \sigma$ & UTS45 & $61.1 \% \sigma$ & UTS45 & $91.6 \% \sigma \quad{ }_{\text {UTS } 45}$ & \\
\hline Strain & 0 & & 0.021 & & 0.082 & & 0.162 & \\
\hline Damage & 0 & & 0.11 & & 0.35 & & 0.53 & \\
\hline
\end{tabular}


(a)

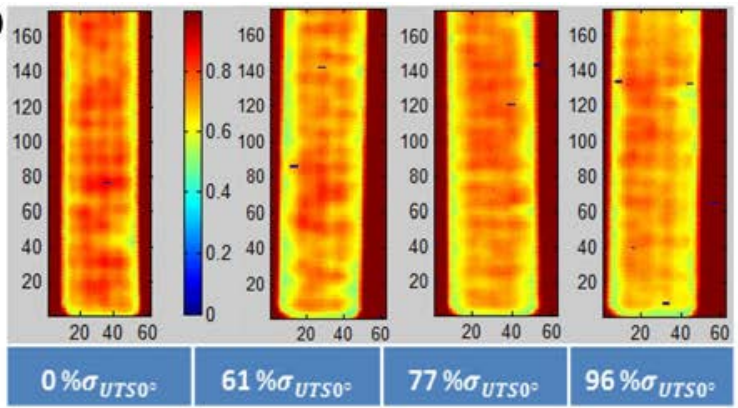

(b)

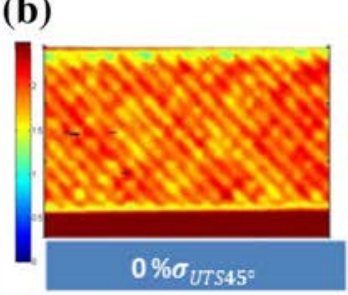

Fibers buckling

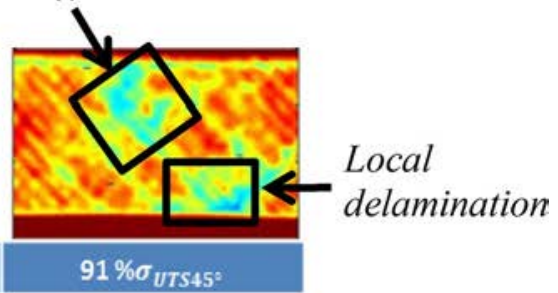

Fig. 7 Preliminary C-scan results on $2 / 2$ twill weave fabric reinforced polyamide composite previously loaded in tension with different amplitude. a Samples in $0^{\circ}$ configuration; b Samples in $45^{\circ}$ configuration. For the latter, besides the large damage zones, one can easily distinguish the $45^{\circ}$ orientation of the yarns

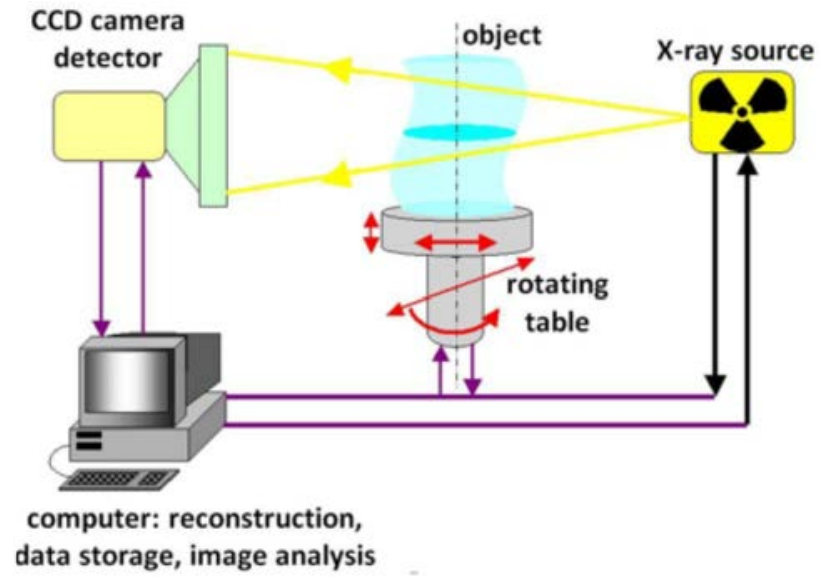

Fig. 8 Principle of the X-ray micro computed tomography techniques [22]

The matrix and the fibers of the composite are characterized by distinctive values of X-ray absorption. Hence, they can be easily separated on a grey level map. Air cannot significantly absorb X-ray. Consequently, the voids cannot be easily observed inside the composite samples, however during the image 3D-reconstruction, the voids appear as completely black volumes. A median filtering was first applied to the raw results to reduce the amount of noise in the images. A despeckle filter was then applied to remove the main part of the remaining interference noise. The different reconstructions were then segmented in three classes (void, matrix and fibers) using a grayscale thresholding. The Avizo software segmentation enables an accurate estimation of the volume fraction of each of the three phases. Figure 9 illustrates an example of a 3D reconstruction of the considered composite material containing an initial porosity.

Prior to a discussion on the evolution of void volume fraction, it must be emphasized that the damage mechanisms have been observed for both considered orientations of samples. A characteristic length of the different damage mechanisms was also determined. Those data are critical to understand the damage scheme of the studied material and to validate the results from the ultrasonic study.

\subsection{Damage Mechanisms}

\subsubsection{Sets of Samples Oriented at $0^{\circ}$ from the Warp Direction}

Some examples of damage mechanisms observed for samples in the $0^{\circ}$ configuration are illustrated in Fig. 10. For tensile tests along the warp fiber axis, the main damage mechanisms observed were the formation of cracks near the end of the yarns (Fig. 10b, c, d), and transverse cracks inside the yarns (Fig. 10a, c), for example). Some longitudinal cracks that follow the transverse yarns very locally in the last step of damage were also observed (Fig. 10d). As the loading level increased, the number and the size of defects (cracks and voids) increased too (Tables 3, 4).

The crack inside the yarns has a characteristic thickness of $20 \mu \mathrm{m}$, which of the order of magnitude of the size of the fibers. Indeed, it is worth noting that those cracks are caused by fiber/matrix debonding, which propagates perpendicularly to the loading direction from one fiber to another. The cracks at the extremities of the yarn have a typical thickness

Table 2 X-ray mCT acquisition parameters

\begin{tabular}{llllll}
\hline Detector resolution & Exposure & Voltage & Voxel size & Focus to detector (FDD) & Focus to object distance (FOD) \\
\hline $2320 * 2336 \mathrm{px}$ & $4 \mathrm{~s}$ & $90 \mathrm{kV}$ & $5.5 \mu \mathrm{m}$ & $670 \mathrm{~mm}$ & $110 \mathrm{~mm}$ \\
\hline
\end{tabular}


Fig. 9 a As received mesostructure of the $2 / 2$ twill weave fabric composite obtained by 3D reconstruction prior to mechanical loading. $\mathbf{b}$ Initial voids and process-induced defects are represented by light color and their content is estimated using Avizo software segmentation (about $0.6 \%$ volume)
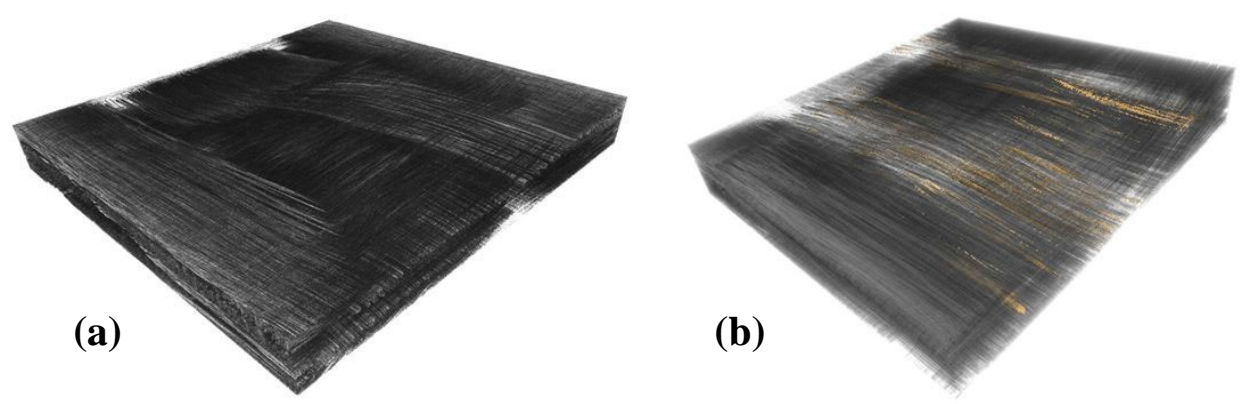

Woven $2 / 2$ twill fabric
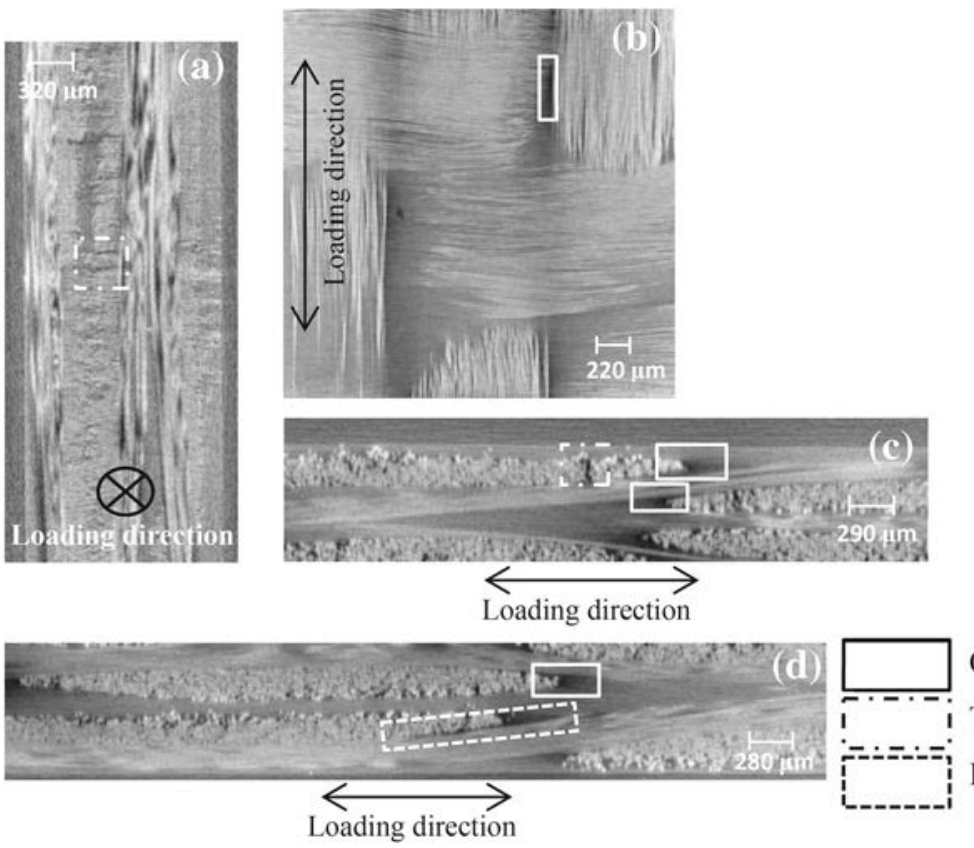

Cracks near the extremities of the yarn Transverse cracks in a yarn Longitudinal cracks

Fig. 10 Three main damage mechanisms identified for $0^{\circ}$ sample configuration under tension loading. These main mechanisms consist in cracks near the extremities of the yarns, transverse cracks in yarns and longitudinal cracks

Table 3 Void volume fraction of the tested samples oriented at $0^{\circ}$ from warp direction

\begin{tabular}{|c|c|c|c|}
\hline \multicolumn{4}{|c|}{ Sample } \\
\hline \multicolumn{4}{|c|}{ Defined loading $\left(\% \boldsymbol{\sigma}_{U T S 0^{\circ}}\right)$} \\
\hline \multicolumn{4}{|c|}{ Void volume fraction (\%) } \\
\hline \multicolumn{4}{|c|}{ tested samples oriented at $0^{\circ}$ from } \\
\hline & 8 & 9 & 10 \\
\hline & 30.5 & 61.1 & 91.6 \\
\hline .59 & 1.69 & 3.04 & 5.51 \\
\hline
\end{tabular}

Table 4 Void volume fraction of the tested samples oriented at $0^{\circ}$ from warp direction

\begin{tabular}{lllll}
\hline Sample & 7 & 8 & 9 & 10 \\
\hline Defined loading $\left(\% \boldsymbol{\sigma}_{U T S 45^{\circ}}\right)$ & 0 & 30.5 & 61.1 & 91.6 \\
Void volume fraction (\%) & 0.59 & 1.69 & 3.04 & 5.51 \\
\hline
\end{tabular}

of $50 \mu \mathrm{m}$ for the highest damaged samples. These longitudinal cracks can then propagate along the warp yarns as shown in Fig. 10d.

\subsubsection{Sets of Samples Oriented at $45^{\circ}$ from the Warp Direction}

For samples in the $45^{\circ}$ configuration, all the observed mechanisms are shown in Fig. 11. Firstly, cracks at the extremities of yarns (visible in Fig. 11a) as well as cracks along the yarns were observed in Fig. 11a, b. On the $91.6 \% \sigma_{U T S 45}{ }^{\circ}$ loaded sample many local fiber breakages were also observed, some of them were already visible in Fig. 11c for the sample tested at $61.1 \% \boldsymbol{\sigma}_{U T S 45^{\circ}}$. Those defects were observed around the central region of the sample, along the loading direction, especially near the edges. In Fig. 11d, some micro buckling 


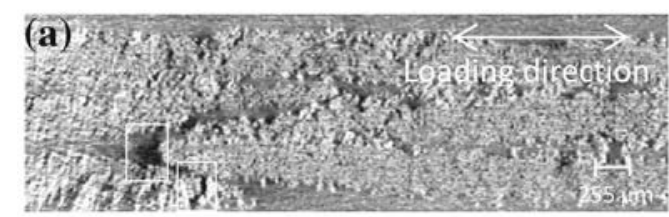

Transverse cracks and cracks near the end of a yarn

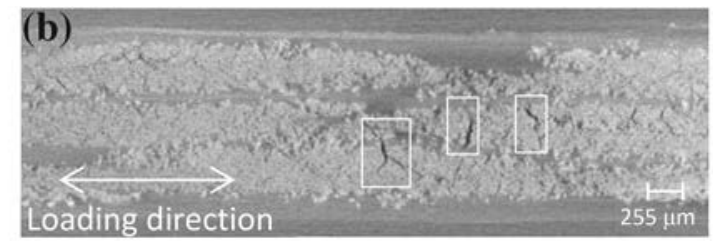

Transverse cracks

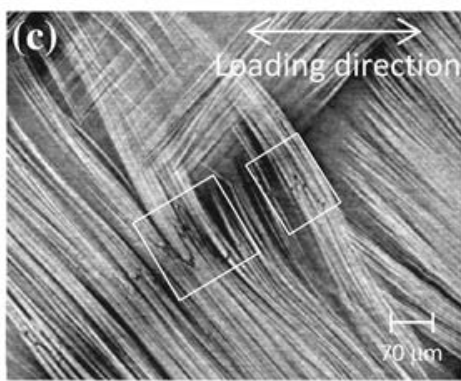

Fibers breakage

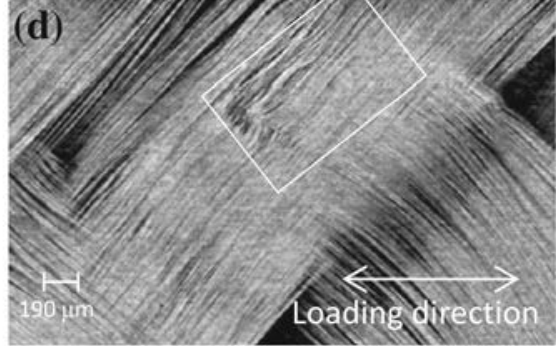

Fibers buckling

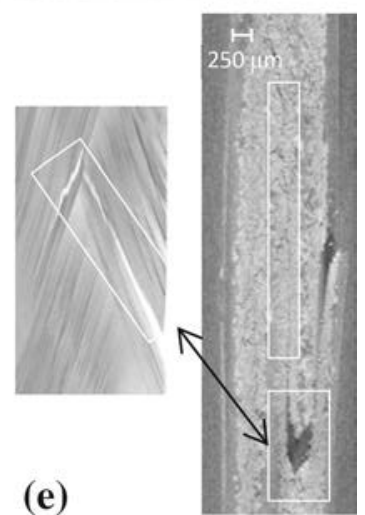

Pseudo-delamination

Fig. 11 The different damage mechanisms that appear when a sample in the $45^{\circ}$ configuration is submitted to tension. These mechanisms consist in transverse cracks, cracks at the extremities of the yarns, fiber breakage, fiber buckling and yarns pseudo-delamination due to the propagation of the longitudinal cracks

of fibers was noted, more notably in the sample loaded at the highest stress level. This is due to the reorientation of fibers during the loading test. Indeed, as the load increases the angle between the fibers tends to decrease but when the tension is interrupted, the fibers cannot return to their original position because of the section reduction caused by the Poisson effect. This effect of the fibers' reorientation during off-axis loading was also observed by Vieille and Taleb [23] among others. Pseudo-delamination also appeared locally after roughly $60.1 \% \boldsymbol{\sigma}_{U T S 45^{\circ}}$ of loading in some specimen, as visible in Fig. 11e. It was propagated inside a yarn and followed the fiber orientation until it reached the location where the weft and warp yarns were intertwined together. When the stress level continued to increase, the crack turned and started propagating along the direction of the other yarn.

It was noticed that the pseudo delamination and fiber buckling were the most important damage mechanisms during this study. These mechanisms are actually the only ones that were detected by the ultrasonic C-scan method described in Sect. 2. They both had a characteristic length of $200 \mu \mathrm{m}$.

\subsection{Micro Computed Tomography Based Void Volume Fraction Estimation}

As previously mentioned, a grey level thresholding, was performed on all the X-ray mCT 3D reconstructions. The evolution of void volume fraction was therefore evaluated. Indeed, the increase of void volume fraction can often be used as a good indicator of damage evolution [24,25].
The evolution of the void volume fraction is plotted for both orientations in Fig. 12. The experimental data $0^{\circ}$ and $45^{\circ}$ configurations are plotted as function of the stress to failure of the $0^{\circ}$ sample (respectively Fig. 12a, b). The Fig. 12c allows an easy comparison of the two results.

The void volume fraction clearly increased with the tension loading level for both considered orientations. However, a higher growth of damage in the set of samples oriented at $45^{\circ}$ from warp direction was observed. In fact, for the samples oriented at $0^{\circ}$ and loaded at $92.6 \% \boldsymbol{\sigma}_{U T S 0^{\circ}}$, a void volume fraction of $1.56 \%$ was measured as it can be seen on the mCT$3 \mathrm{D}$ reconstruction in Fig. 13. On the other hand, as shown in Fig. 14, for the sample tested at $45^{\circ}$ for a stress level of $91.6 \% \boldsymbol{\sigma}_{U T S 45^{\circ}}{ }^{\circ}$, the estimated volume void content was about $5.51 \%$. These results are in agreement with the difference in terms of the behavior between the two sample's orientations discussed in Sect. 2. Indeed, the overall response of the $45^{\circ}$ samples was more ductile compared to the behavior of a sample tested at $0{ }^{\circ}$, which exhibited a linear elastic brittle behavior.

The evolution of the void volume fraction as a function of the applied stress level (Fig. 12c) exhibited a similar increase as the evolution of the macroscopic damage estimated from the Young's modulus reduction plotted in Fig. 6. Accordingly, these two quantitative estimations of the damage state, namely void volume content and Young's modulus reduction will be two actual measurements of the damage that validate the proposed new damage indicators.

Qualitatively, Fig. 13b shows a clear preferred orientation of the damage accumulation, which is perpendicular to the 

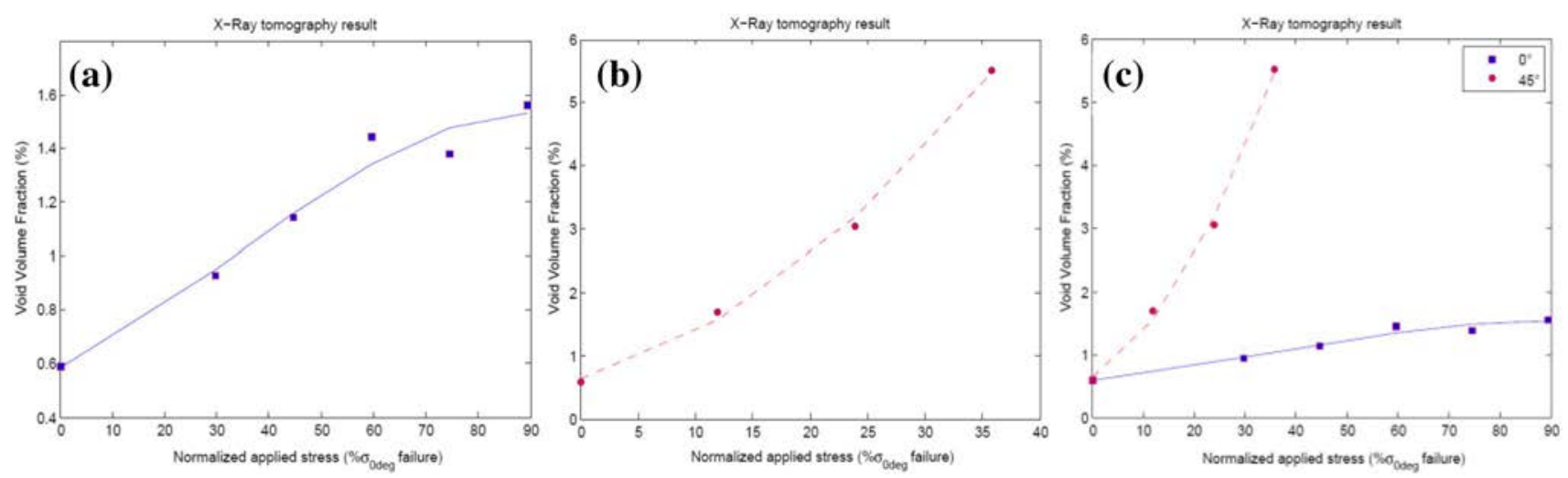

Fig. 12 Evolution of void volume fraction for $\mathbf{a} 0^{\circ}$ and $\mathbf{b} 45^{\circ}$ configuration of sample with increasing loading. In $\mathbf{c}$ data of both configurations are plotted for comparison purpose

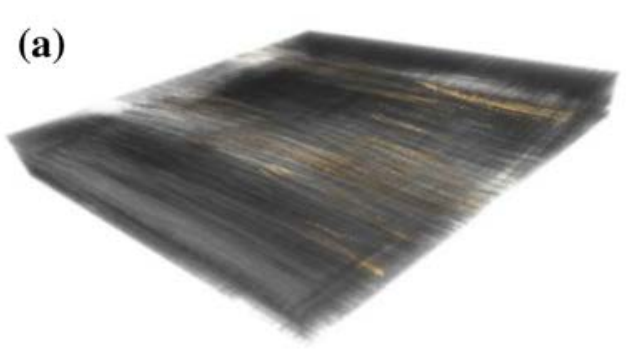

Initial void in an as received sample. The volume void content estimated was $0.5 \%$ (b)

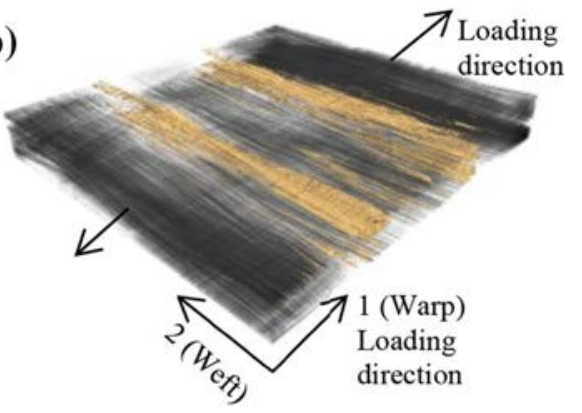

Voids and defects (damage) induced by the tension loading at $0^{\circ}$. The volume void content estimated for a stress level of $92.6 \% \sigma_{U T S 0^{\circ}}$ was $1.56 \%$

Fig. 13 mCT-3D reconstructions of composite samples in the $0^{\circ}$ configuration respectively a before and $\mathbf{b}$ after tensile loading at a stress level of $92.6 \% \sigma_{\mathrm{UTS}}{ }^{\circ}$

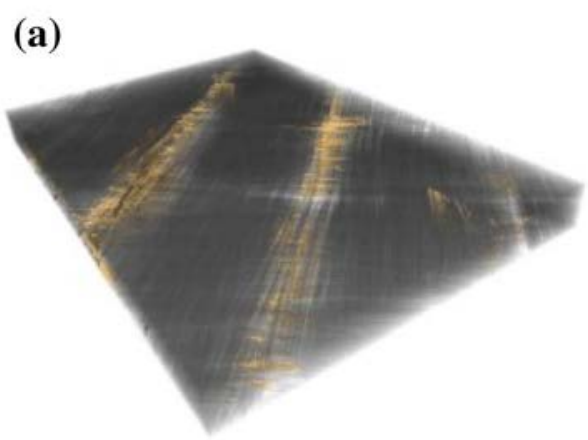

Initial void in an as received sample. The initial volume void content estimated was $0.6 \%$

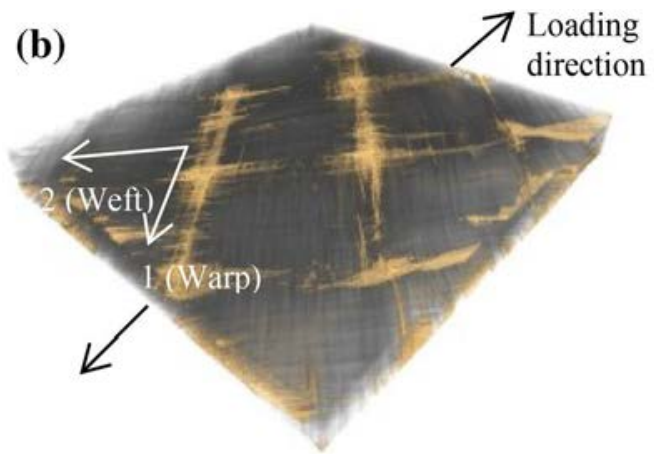

Voids and defects (damage) induced by the tension loading at $45^{\circ}$. The volume void content estimated for a stress level of $91.6 \% \sigma_{U T S} 0^{\circ}$ was $5.51 \%$

Fig. 14 mCT-3D reconstructions of composite samples in the $45^{\circ}$ configuration respectively a before and $\mathbf{b}$ after tensil loading at a stress level of $91.6 \% \sigma_{\mathrm{UTS}}{ }^{\circ}$

tension loading direction for the samples oriented along the warp direction $\left(0^{\circ}\right)$. In the case of the $45^{\circ}$ samples, thecracks grow along the two yarns direction as visible in the Fig. 14b.
It is worth noting that the estimation of void volume fraction and the observation of the damage mechanisms were performed after unloading to zero force (elastic release). 
Therefore, some of the opened cracks could be partially closed during the unloading and hence cannot be observed. Consequently, the actual void volume content may be to some extent higher than what was measured in the present study. This is especially the case for the $0^{\circ}$ configuration samples. For the $45^{\circ}$ configuration, there is permanent deformation and higher presence of matrix permanent strain at high loading levels reduced the cracks closure effect.

\section{Stiffness Components Measurements}

Various methods based on ultrasonic wave propagation measurements can be utilized to detect the damage in composite materials. It was shown in Sect. 2 that the widely used ultrasonic C-scan imaging technique may be inefficient to detect the early damage stages for the composite samples oriented at $0^{\circ}$ and $45^{\circ}$. As a first approach, a measurement of stiffness components using wave velocity propagation was considered in this section to measure the damage evolution. This stiffness components measurement method is described in the first sub-section. Results on samples oriented at $0^{\circ}$ and $45^{\circ}$ from warp direction are then presented in further sub-sections and compared. Because of the samples' low thickness, guided waves propagation is considered for some of the measured signals, further below called plane 1-2; Whereas bulk waves measurement in transmission are treated for the remaining part of the measured signals, propagating in what we will call, further down, the plane 1-3. The procedure is described in the following sub-section. The difference in approach is of course linked to whether waves propagate as guided waves in the plate or pass through as bulk waves.

\subsection{Principle of the Method}

The main idea of this method is to measure the velocity of wave propagation at different incidence angles on different principal planes. Indeed, it can be shown that, for plane waves, the velocity of wave propagation trough a solid homogenous medium is a function of the stiffness and density of the sample via the following equation, also known as the Christoffel's equation:

$$
\left(C_{i j k l} n_{k} n_{j}-\rho V_{p}^{2}{ }_{i j}{ }^{\ddagger}{ }_{U_{l}}=0\right.
$$

Where $\mathbf{C}$ is the stiffness tensor, $\mathbf{n}$ is the vector normal to the plane of the wave (i.e. $\mathbf{n}$ is a vector in the direction of phase propagation), $\rho$ is the material's density, $\boldsymbol{V}$ is the phase velocity, $\boldsymbol{U}$ is the polarization vector of the mechanical wave and $\delta$ is the Kronecker delta symbol.

Depending on the incidence angle, various wave modes may appear. Indeed, by solving the Christoffel equation, one can find three different theoretical bulk wave modes: Quasi-Longitudinal, a fast Quasi-Transversal 1 and a slow Quasi-Transversal 2. The QL has a polarization primarily parallel to the direction of $\mathbf{n}$, whereas the QT has a polarization primarily perpendicular to the direction of $\mathbf{n}$.

In order to use this Christoffel's equation to describe the relation between the velocities of wave propagation inside the material and its stiffness components, these components must not depend on the position inside the material i.e. the material must be considered as a homogenous medium [26]. Therefore, the wavelength of the propagating wave must exceed the smallest microstructural features of the undamaged composite i.e. the fibers.

From an experimental point of view, the velocity of waves traveling through the sample is obtained by calculating the time delay $\delta_{t}$, whether positive or negative measured using an experimental set-up in transmission, visible in Fig. 15b . The latter provides the difference between the time of flight (ToF) of the wave from the emitter to the receiver with the sample and the time of flight of the ultrasonic waves in water (without the sample). So, a first wave time travel measurement, without the sample, needs to be performed and used as a reference. Then, the two following equations are used to calculate, respectively, the refraction angle $\theta_{\mathrm{r}}$ and the wave phase velocity $\mathrm{V}_{\mathrm{P}}$ :

$$
\begin{aligned}
& \theta_{r}=\operatorname{atan} \frac{1}{\cos \left(\theta_{i}\right)-{ }^{V_{0} \delta_{t}}}{ }^{\#} \\
& V_{p}=\frac{V_{0} \sin \left(\theta_{r}\right)}{\sin \left(\theta_{i}\right)}
\end{aligned}
$$

The values are calculated for all considered incidence angles in the plane 1-3 (defined in Fig. 15b).

Because of the dimensions of the samples, measurements of bulk waves in transmission in plane 1-3 were performed but not in the plane $2-3$. In order to have sufficient measurements to compute at least 7 stiffness constants, additional measurements in the 1-2 plane, (azimuth plane defined in Fig. 15a), were performed. Indeed because of the small thickness of the sample, bulk wave measurement in transmission cannot be done since it may cause the sound passing by the sample and not passing through the sample while rotating the emitter-receiver couple. As a consequence, the ultrasonic waves propagating in this plane are guided waves that are described by other sets of equations.

Indeed, one must be sure that correct descriptors of the acoustic fields inside the plate are considered. For the first arriving pulse passing through the plate along the shortest (straight) path between two transducers facing each other, plane waves are considered responsible of the measured through transmitted pulse. However, guided waves or later 
Fig.15 Schematic representation of the two planes of interest: a the plane 1-2 or azimuth plane and $\mathbf{b}$ the plane $1-3$

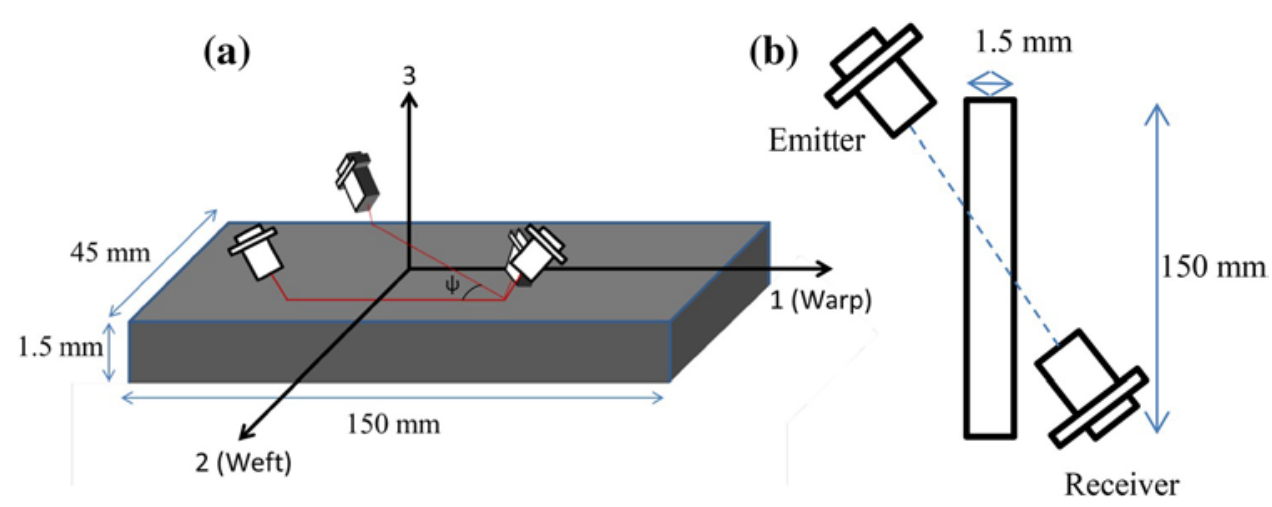

arriving pulses caused by multiple scattering phenomena cannot be described as plane waves.

In the plane 1-3, considered first, such bulk plane wave approach is acceptable and typically performed, however when guided waves are therefore used in the plane $1-2$, we are obliged to use more complicated expressions for guided waves that will be described further below. In fact, guided waves, contrary to the bulk waves described above, are known to be dispersive, and accordingly their phase velocities are function of the frequency and sample thickness, in addition to the material properties. In addition, this dispersive effect induces a phase velocity and a group velocity of the guided waves modes different from one another which affect the interpretation of measured signals.

Although theoretically they can be linked through the same Christoffel's equation through a plane wave expansion of the acoustic field, experimentally one must take caution as to not confuse one by the other.

Specific experimental procedures must be used if measurements of the first or the second velocity is required. Group velocity is usually obtained by ToF measurements on a specific peak in the wave signal for two distances between emitter and receiver (or time-delay measurement). An experimental set-up different from the first one presented and depicted in Fig. 15a is used for acquiring the phase velocities in the plane 1-2. This set-up in immersion using two transducers in pitch-catch, both at a chosen incidence/reflection angle, can be used to measure the phase velocities $[27,28]$. The phase velocities $\mathrm{V}_{\mathrm{LWP}}$, in the plane of the plate, for Lamb waves, are then obtained with the use of the Snell's law with $\theta_{r}=90^{\circ}$ i.e. equation (4) transforms into:

$$
\begin{gathered}
V \quad \frac{V_{0}}{(5)} \\
L w p=\sin (\theta)
\end{gathered}
$$

For each azimuthal direction of propagation $(\Psi)$ in the 12 plane, the incidence angle is adjusted in order to find the same guided wave mode at every acquisition. If the time of arrival would be used, as in the bulk wave approach, then group velocity. However, when the time of arrival is used in the Sect. 5.2, a phase shift is then extract as is and not convert to velocity.

The two experimental set-ups are depicted in Fig. 15. The relation between the frequencies and the group/phase velocities is usually represented on dispersion curves. They were computed for propagation in the considered composite sample along the direction of the fibers using the commercially available Disperse software and are visible in the Fig. 16. The frequency spectrum of every recorded signal is also carefully measured to compare the experimental results with numerical dispersion curves.

Because guided waves propagation along off-principles planes will be considered, the guided wave equations, in explicit format, are needed to be given for a monoclinic stiffness tensor. The latter is obtained with a rotation along the axis 3 at a chosen angle of the orthotropic stiffness matrix. In this case, the equations of motion are defined with the following systems of equations. Please note that for more details about the guided waves characteristic equations the reader can refer to the book of Nayfeh [29].

$$
\begin{gathered}
C_{11} \frac{\partial^{2} u}{\partial x_{1}^{2}}+C_{44} \frac{\partial^{2} u}{\partial x_{2}^{2}}+C_{55} \frac{\partial^{2} u}{\partial x_{3}^{2}} \\
+2 C_{14} \frac{\partial^{2} u_{1}}{\partial x_{1} \partial x_{2}}+C_{14} \frac{\partial^{2} u_{2}}{\partial x^{2}}+C_{24} \frac{\partial^{2} u_{2}}{\partial x^{2}}+C_{56} \frac{\partial^{2} u_{2}}{\partial x^{8}} \\
\left(C_{12}+C_{44}\right) \frac{\partial^{2} u_{2}}{\partial x_{1} \partial x_{2}}+\left(C_{13}+C_{55}\right) \frac{\partial^{2} u_{3}}{\partial x_{1} \partial x_{3}} \\
+\left(C_{34}+C_{56}\right) \frac{\partial^{2} u_{3}}{\partial x^{2} \partial x^{3}}=\frac{\partial^{2} u_{1}}{\partial t^{2}}
\end{gathered}
$$

$$
\begin{aligned}
& C_{14} \frac{\partial^{2} u_{1}}{\partial x_{1}^{2}}+C_{24} \frac{\partial^{2} u_{1}}{\partial x_{2}^{2}}+C_{56} \frac{\partial^{2} u_{1}}{\partial x_{3}^{2}} \\
& +\left(C_{12}+C_{44}\right) \frac{\partial^{2} u_{2}}{\partial x_{1} \partial x_{2}}+C_{44} \frac{\partial^{2} u_{2}}{\partial x_{1}^{2}}+C_{22} \frac{\partial^{2} u_{2}}{\partial x_{2}^{2}}
\end{aligned}
$$

one has to remember that this time is actually 
linked to the

$$
+C_{66} \frac{\partial^{2} u_{2}}{\partial x^{3}}+2 C_{24} \frac{\partial^{2} u_{2}}{\partial x_{1} \partial x_{2}}+\left(C_{34}+C_{56}\right) \frac{\partial^{2} u_{3}}{\partial x^{1} \partial x^{3}}
$$



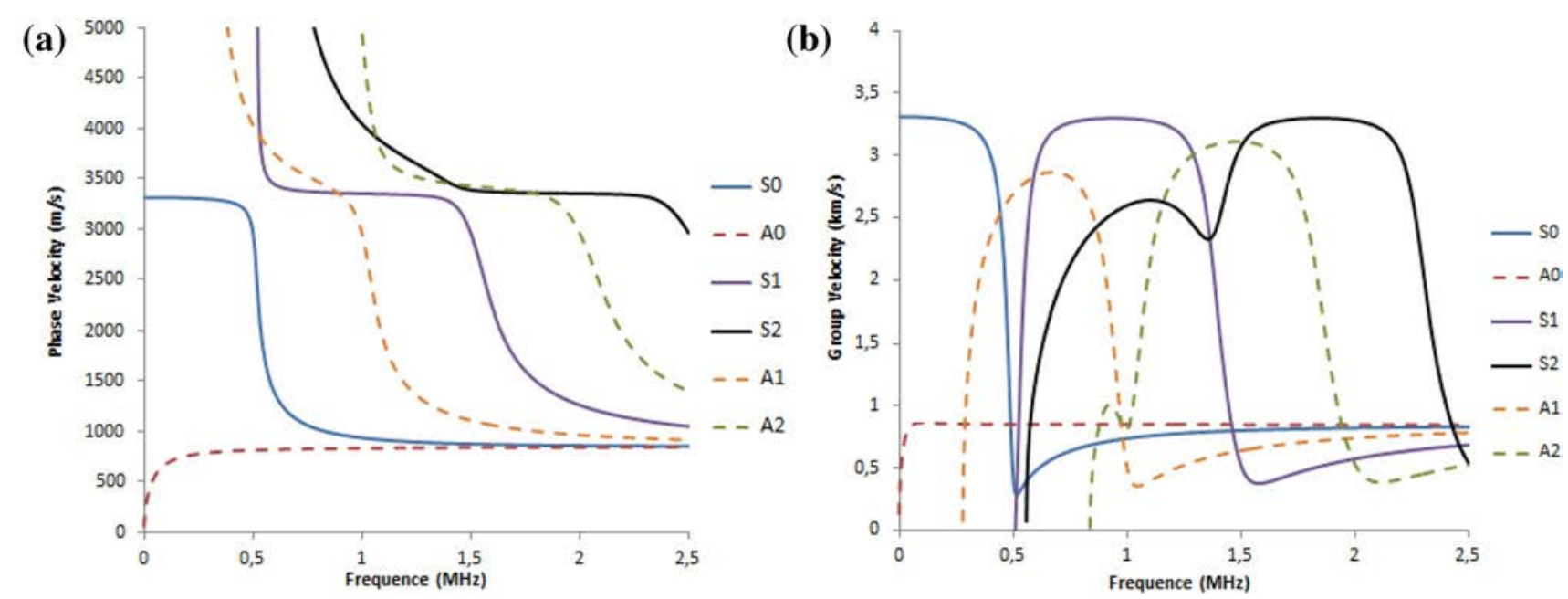

Fig. 16 Dispersion curves computed with the Disperse software for guided wave propagation in a 1.53mm thick studied composite along the fibers direction. a Phase velocities, $\mathbf{b}$ group velocities

$$
\begin{aligned}
& +\left(C_{23}+C_{66}\right) \frac{\partial^{2} u_{3}}{\partial^{2} u_{1} x^{2} \partial x^{3}}=\frac{\partial^{2} u_{1}}{\partial t^{2}} \\
& \left(C_{13}+C_{55}\right) \frac{\partial^{2} u_{1}}{\partial x^{1} \partial x^{3}}+\left(C_{34}+C_{56}\right) \frac{\partial^{2} u_{2}}{\partial x^{2} \partial x^{3}} \\
& +\left(C_{34}+C_{56}\right) \frac{\partial^{2} u_{2}}{\partial x^{1} \partial x^{3}}+\left(C_{23}+C_{66}\right) \frac{\partial^{2} u_{3}}{\partial x^{1} \partial x^{2}} \\
& +C_{55} \frac{\partial^{2} u_{3}}{\partial x_{1}^{2}}+C_{66} \frac{\partial^{2} u_{3}}{\partial x_{2}^{2}}+C_{33} \frac{\partial^{2} u_{3}}{\partial x_{3}^{2}} \\
& +2 C_{56} \frac{\partial^{2} u_{3}}{\partial x^{1} \partial x^{2}}=\frac{\partial^{2}}{\partial t^{2}}
\end{aligned}
$$

Based on those wave equations the following guided waves characteristic equations can consequently be obtained:

$$
\begin{aligned}
A= & D_{11} G_{1} \tan \left(\gamma \alpha_{1}\right)-D_{13} G_{3} \tan \left(\gamma \alpha_{3}\right) \\
& +D_{15} G_{5} \tan \left(\gamma \alpha_{5}\right)=0
\end{aligned}
$$$$
\text { for the antisymmetric modes }
$$$$
)
$$

$$
\begin{aligned}
S= & D_{11} G_{1} \cot \left(\gamma \alpha_{1}\right)-D_{13} G_{3} \cot \left(\gamma \alpha_{3}\right) \\
& +D_{15} G_{5} \cot \left(\gamma \alpha_{5}\right)=0 \\
& \text { for the symmetric modes }
\end{aligned}
$$

$\alpha_{q ; q=1,3,5}$ being the solution of the wave equations when the displacement field is of the forms $u_{j}=U_{j} e^{i \xi\left(x_{1}+\alpha x_{3}-c t\right)}$.

Here $\mathrm{U}_{j}$ is the wave amplitude, $c$ is the guided wave phase velocity, $\xi$ is the wavenumber and $y=\xi \mathrm{d} / 2=\pi \mathrm{fd} / \mathrm{c}$ where $\mathrm{d}$ is the sample's thickness and $\mathrm{f}$ the wave frequency.

Finally $\mathrm{G}_{\mathrm{i}}$ and $\mathrm{D}_{\mathrm{iq}}$ are given by:

$G_{1}=D_{23} D_{35}-D_{33} D_{25}$
And

$$
\begin{gathered}
D_{1 q}=C_{13}+C_{34} V_{q}+C_{33} \alpha_{q} W_{q} \\
D_{2 q}=C_{55}\left(\alpha_{q}+W_{q}\right)+C_{56} \alpha_{q} W_{q} \\
D_{3 q}=C_{56}\left(\alpha_{q}+W_{q}\right)+C_{66} \alpha_{q} W_{q}
\end{gathered}
$$

The amplitude ratio $V_{q}$ and $W_{q}$ are given by

$$
V^{q}=U_{1 q}^{2 q} \text { and } W q=\frac{U_{3 q}}{U_{1 q}}
$$

An overdetermined minimization problem can then be defined. This problem is classically solved by considering a least squares method approach and using a LevenbergMarquardt algorithm. The stiffness copnponents can be obtained by minimizing the functional $F C_{i j}$ defined as: ${ }_{F}\left(C_{i j}\right)=\left[V_{\text {exp }}-V_{\text {num }}\left(C_{i j}\right)_{2}\right.$ $n$

with $n$ : the number of experimental velocities

$G_{2}=D_{21} D_{35}-D_{31} D_{25}$
$G_{3}=D_{21} D_{33}-D_{31} D_{23}$ 
The numerical velocities are determined by solving the

Christoffel equation and the guided waves characteristic equations for a given set of $C_{i j}$. In order to avoid finding a local minimum solution, it is important to initiate the algo- rithm with a first guess of $C_{i j}$ that is relatively close to the real solution.

In this paper, the initialization values of the algorithm are calculated by periodic homogenization computation [30], they are indicated in Table 5. The values of identified stiff- ness components depend on this initial guess but also on the number of experimental velocities considered and the num- ber of principal planes investigated. Therefore it is necessary 
Table 5 Comparison between numerical and experimental results of the stiffness constants for undamaged glass fiber reinforced woven composite

\begin{tabular}{|c|c|c|c|c|c|c|c|c|c|}
\hline & $\mathrm{C}_{11}$ & $\mathrm{C}_{12}$ & $\mathrm{C}_{13}$ & $\mathrm{C}_{22}$ & $\mathrm{C}_{23}$ & $\mathrm{C}_{33}$ & $\mathrm{C}_{44}$ & $\mathrm{C}_{55}$ & $\mathrm{C}_{66}$ \\
\hline Numerical (periodic homogenization) & 20 & 2.1 & 1.5 & 20 & 1.5 & 4.5 & 2.3 & 1.3 & 1.3 \\
\hline Experimental & $22.21(0.2)$ & $2.57(0.15)$ & $1.41(0.76)$ & $21.81(0.08)$ & - & $4.1(0.07)$ & $2.33(0.09)$ & $1.58(0.21)$ & - \\
\hline
\end{tabular}

The numbers between parentheses are the confidence intervals
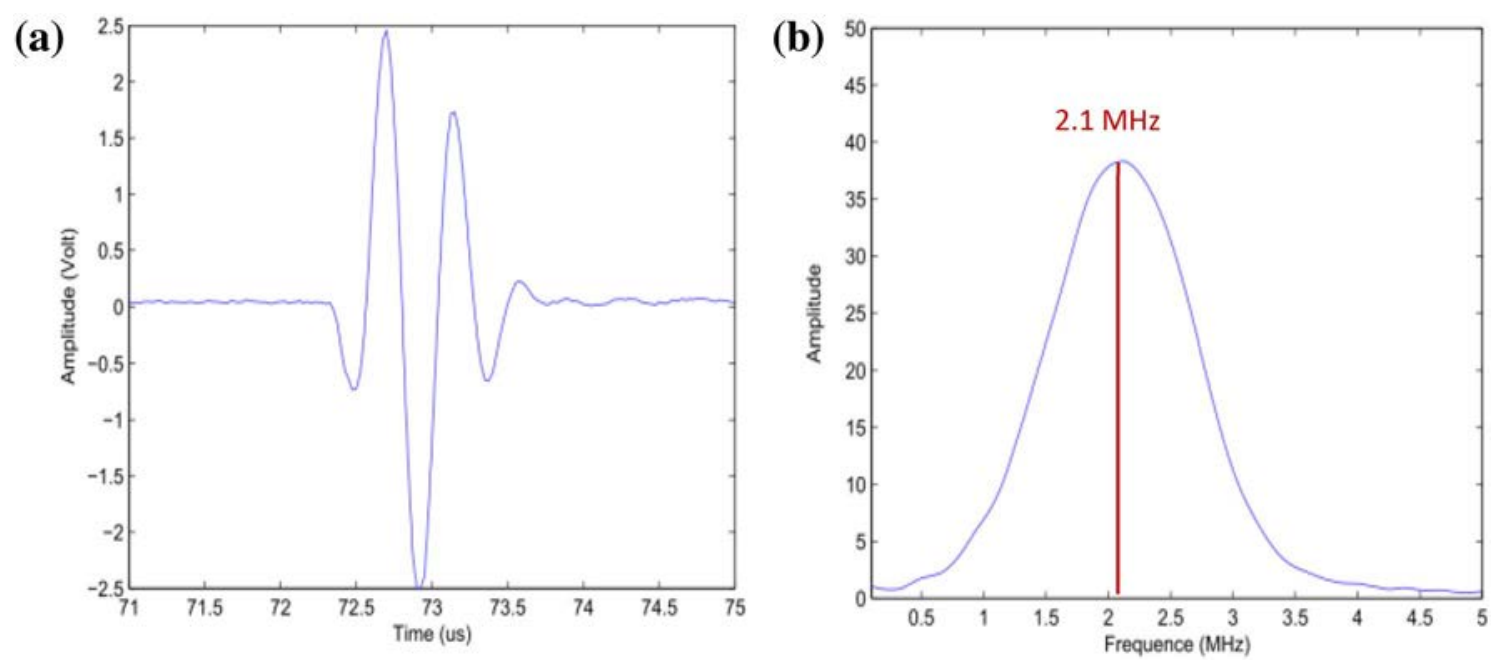

Fig. 17 a Emitted pulse signal and spectrum $\mathbf{b}$ for a $2.25 \mathrm{MHz}$ center frequency transducer. The experimentally mesured center frequency is about $2.1 \mathrm{MHz}$

to estimate a confidence interval, $c i(i)$, for each component of the identified stiffness matrix. It was proposed by Audoin et al. [31] to use the covariance matrix $\varphi$ to obtain statistical information of the deviation from the analytical solutions for each stiffness component. This covariance matrix is calculated as:

$$
\boldsymbol{\varphi}=\frac{\boldsymbol{r}^{t} * \boldsymbol{r}}{n^{t}-m} *([\boldsymbol{J}] *[\boldsymbol{J}])^{-}
$$

where: $[\boldsymbol{J}]=\frac{\partial F\left(C_{i j}\right)}{\partial C_{i j}}$ is the Jacobian matrix, $\mathbf{r}$ is the vector of the residual values i.e. the functional evaluated with the identified solution, $\mathrm{n}$ is the number of experimental velocities and $m$ is the number of stiffness parameters to be identified.

The values of confidence interval can then be extracted from the diagonal terms of the covariance matrix.

$c i(i)={ }^{j} \overline{\varphi i i}$

The acquisitions were carried out using a customer-designed five axes immersion scanner fabricated by Inspection Technology Europe BV. The pulses were emitted by the dual pulser-receiver DPR500 made by JSR ultrasonics. The experimental data were acquired with Winspect software and were post-processed with Matlab. An immersion Panasonic transducer with a central frequency of $2.25 \mathrm{MHz}$ was used in order to satisfy the homogenous media hypothesis. The shape and the spectrum of the emitted pulse are represented at Fig. 17.

\subsection{Application to Sets of Samples Oriented at $0^{\circ}$ from the Warp Direction}

The composite is considered as orthotropic prior to loading and remains so even after the damage induced by the tensile loading. The elastic linear behavior of the composite can be described using nine stiffness components. However, considering the dimensions of the sample, only measurements in two principal planes were performed as illustrated in Fig.

15. These measurements only permitted obtaining seven out of nine stiffness components. It was observed that along the plane $1-3$, quasi longitudinal and quasi transversal mode 1 can be measured. For the plane 1-2, on which guided waves propagate, the frequency and phase velocity of the transmitted signal was measured. Consequently, after comparison with the dispersion curves in Fig. 16, the mode S2 was propagating in the composite.

Before running the optimization procedure for obtaining the stiffness constants, a computation of the expected velocity as a function of the incidence angle was performed. The quasi longitudinal, the quasi transversal 1 and the quasi transversal 2 modes propagated in the 1-3 principleplane were calculated for a refraction angle ranging from 0 to $90^{\circ}$. This computation was based on the stiffness matrix obtained by periodic 

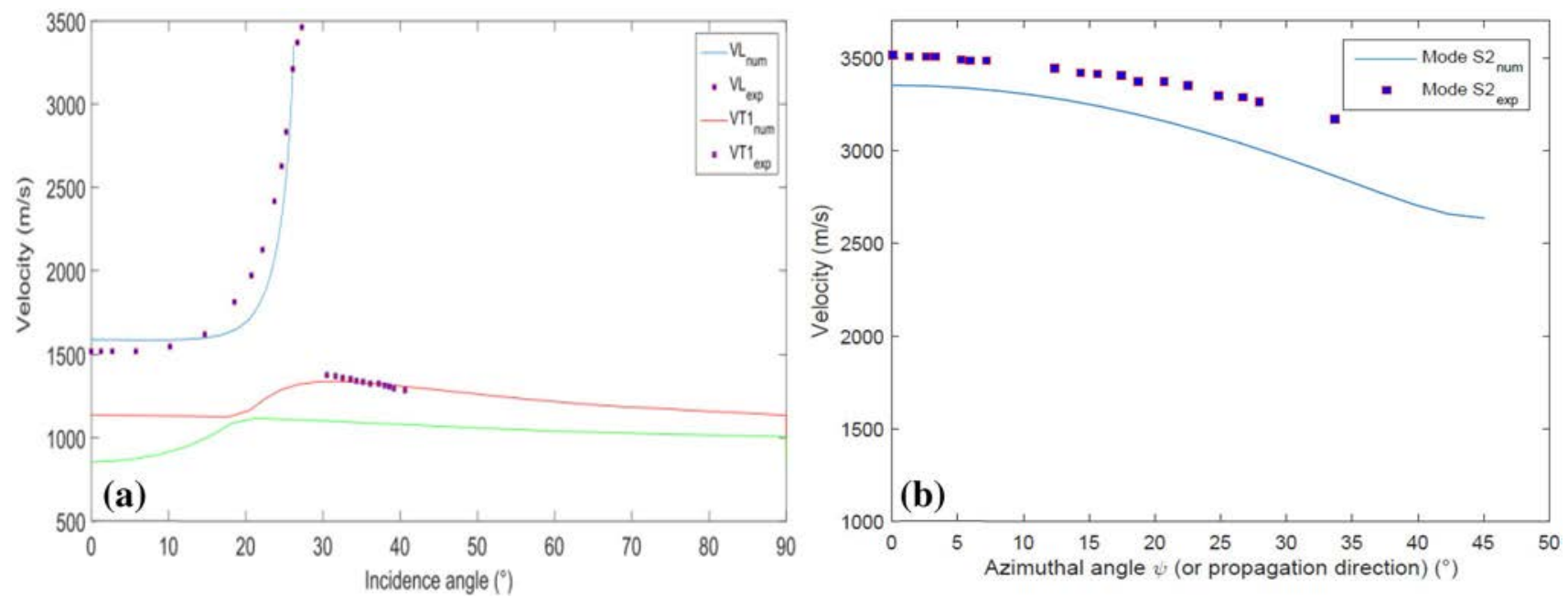

Fig. 18 Comparison of numerically and experimentally determined propagation wave velocities. The experimental values are represented by points whereas numerical values are represented in continuous line. a Plane 1-3; b Plane 1-2 or azimuth plane

C11 and C22

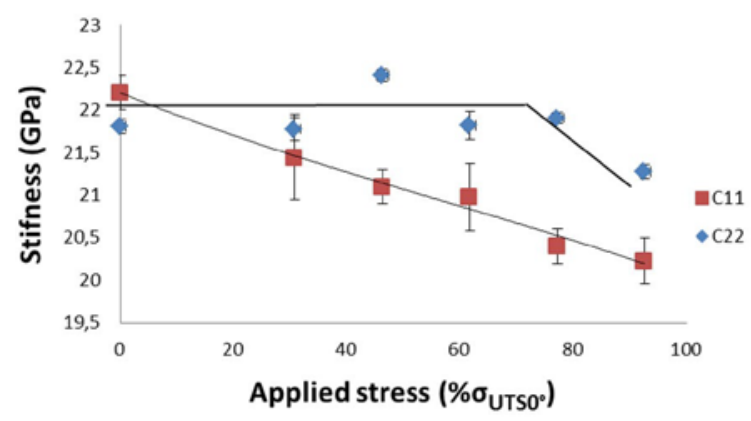

C12 and C44

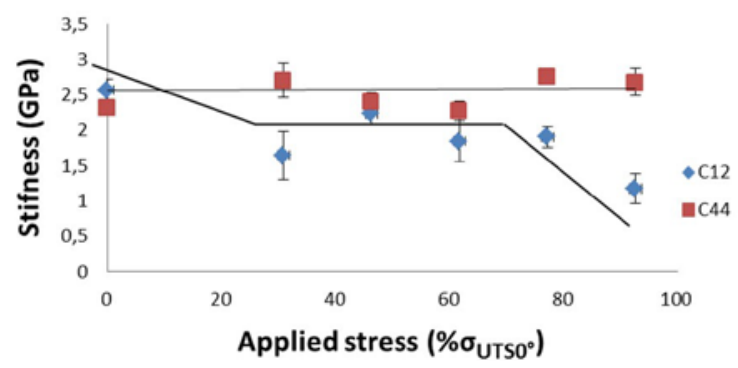

C33

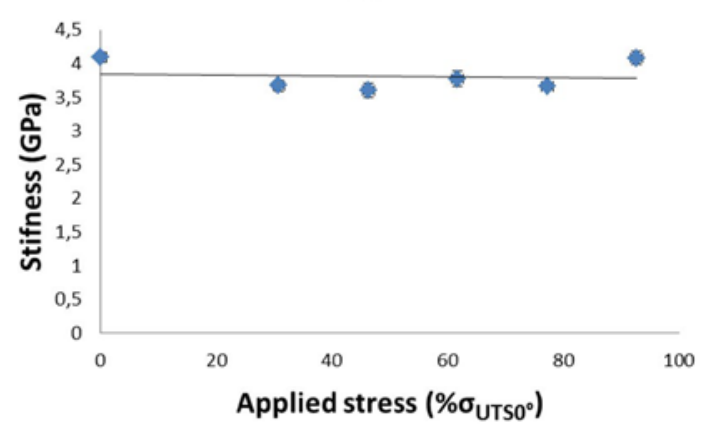

C13 and C55

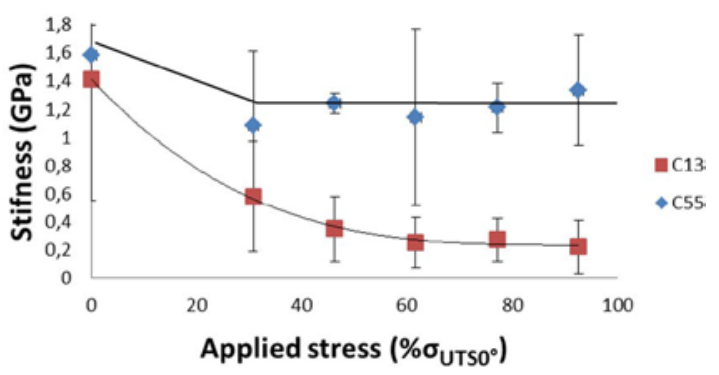

Fig. 19 Evolution of seven of the stiffness constants, function of the tensile stress, with the increase of the loading for the $0^{\circ}$ configuration of sample with their respective confidence interval

homogenization (Table 5). The computed velocities were compared to those obtained experimentally for the undamaged sample. The same calculation was made for Lamb wave propagation in the 1-2 planes, more particularly for the S2 mode. The comparison of experimental and analytical velocities of wave propagation is illustrated in Fig. 18. It confirms that the mode experimentally measured corresponds to the actual wave mode that was assumed to propagate in the composite material.
For the undamaged sample oriented along the warp direction $\left(0^{\circ}\right)$, the experimental stiffness constants were close to the numerically obtained results as observed in Table 5. The evolution of the stiffness constants is plotted in the Fig. 19 with their respective confidence interval. Furthermore, it was noticed that the global evolution of the stiffness components was close to the results discussed by Hufenbach et al. [9]. An important decrease of the components $\mathrm{C}_{11}$ and $\mathrm{C}_{13}$ was noticed, whereas a smaller decrease of $\mathrm{C}_{12}$ and $\mathrm{C}_{55}$ and 
almost no change of $\mathrm{C}_{33}, \mathrm{C}_{22}$ and $\mathrm{C}_{44}$ compared to the other stiffness components is remarked (Fig. 19).

One can then conclude that the components depending on the loading direction (direction 1 ), namely $\mathrm{C}_{11}$ and $\mathrm{C}_{13}$ were more affected by the damage. The component $\mathrm{C}_{12}$ was also impacted by the damage but at a lower extent.

\subsection{Application to Sets of Samples Oriented at $45^{\circ}$ from the Warp Direction}

In the $45^{\circ}$ configurations, another propagation plane, named $\mathrm{X}-3$ is considered (defined in Fig. 20). The latter is oriented at $45^{\circ}$ from the plane $1-3$ used in the $0^{\circ}$ configuration. Indeed, when the sample is oriented at $45^{\circ}$ from the warp direction, the axis of the sample will correspond to the axis of the plane $\mathrm{X}-3$. The different planes of propagation are illustrated in the Fig. 20. The $X-3$ plane is not a principal plane of the composite but remains an axis of symmetry in its undamaged state. The same procedure can then be applied. However, when submitted to tension at $45^{\circ}$ from the warp direction, the damage induced in the sample can introduce loss in elastic symmetry. This can be provoked by the fiber's reorientations or unexpected micro cracks perpendicular to the loading direction; even though the Fig. 14b indicates that the majority of the damage is appearing along the two fiber axis (i.e. $-/+45^{\circ}$ ). Therefore, to describe the elastic behavior of the samples oriented at $45^{\circ}$ with respect to the warp direction, thirteen stiffness components are necessary. The Christoffel equation is consequently modified by considering $\mathrm{C}_{56}, \mathrm{C}_{14}, \mathrm{C}_{24}$ and $\mathrm{C}_{34}$ components for the stiffness tensor. However, ultrasonic measurements in four planes are needed to have a good estimation of these thirteen stiffness components. Some nonnegligible errors may result from this limitation in the number of measurements.

The evolution of the stiffness components is plotted in Fig. 21 with their respective confidence interval. During the first steps of the loading, the components that are a function of the loading direction (especially $\mathrm{C}_{11}$ and $\mathrm{C}_{13}$ ) did not change at

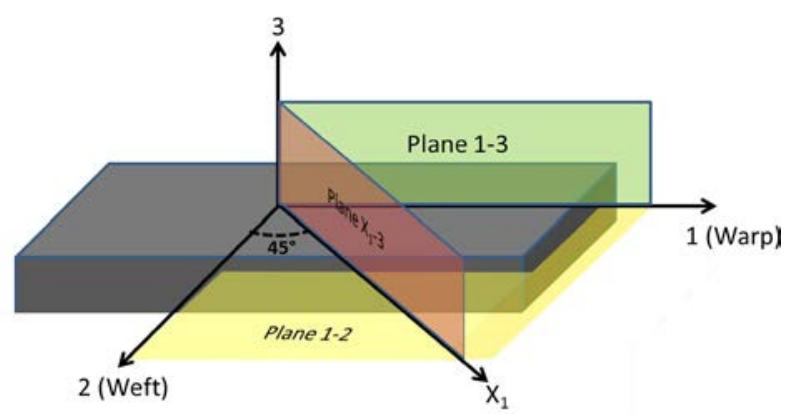

Fig. 20 Schematic representation of the different propagation planes of ultrasonic waves. For samples in the $0^{\circ}$ configurations, the planes $1-3$ and $1-2$ were used. For the samples in the 45 configuration, the plane X-3 and 1-2 (or azimuth plane) were used all, but they dropped drastically after $61.1 \% \boldsymbol{\sigma}_{\text {UTS }} 45^{\circ}$. The shear components $\mathrm{C}_{44}$ and $\mathrm{C}_{12}$ were of course impacted from the beginning of the test. The components $\mathrm{C}_{33}$ and $\mathrm{C}_{55}$ did not really change during the tensile tests. This led to a very different damage behavior compared to the other sample configurations. Some minor changes were observed for the $\mathrm{C}_{56}, \mathrm{C}_{14}, \mathrm{C}_{24}$ and $\mathrm{C}_{34}$ components. However, the confidence interval was very large when compared to the other stiffness components. This is explained by the lack of measurement in two additional planes as mentioned earlier. The major impact from the loading on the shearing components was clearly detected with the present method. Furthermore, this was in agreement with the damage mechanisms observed in the previous section. Indeed, it is worth recalling that the fiber buckling was caused by the reorientation of the fibers which was induced by important local shearing in the mesostructure.

This method can be used to obtain non-destructively the evolution of the stiffness components on a structure submitted to various complex solicitations schemes without performing post-loading tensile tests. This is a significance help for non-destructive damage evaluation.

In the present ultrasonic study, a complete 3D characterization of the stiffness tensor for different damage states was obtained via the velocity of wave propagation through the composite material. An anisotropic evolution of damage different from one another was observed for each of the both samples configurations. In addition, the sensitivity of the chosen method to detect and quantify different damage scheme was verified. However, it is necessary to note the influence of cracks closed effect that may reduce the amount of damage that can be efficiently quantify. Even if X-ray tomography results indicated the presence of an increasing amount of defects, the stiffness reduction measurements in the present study were only representative of the cracks that remain open after unloading to zero force. As mentioned earlier, the 0 configuration might be concerned by this effect at a higher extent than the $45^{\circ}$ configurations.

It is clear that this leads to an excessive amount of information that may be difficult to analyze quickly in terms of global damage state. For this reason, two damage indicators are considered in the next section to provide information that could be more easily interpreted in terms of global damage state of a sample.

\section{Proposition of New Ultrasound Based Damage Indicators}

In the previous section it was shown that damage growth can be detected and quantified via measurement of wave velocities. This allowed obtaining an almost complete stiffness tensor for each sample. However, it still remains difficult to 
$\mathrm{C}_{11}$ and $\mathrm{C}_{22}$

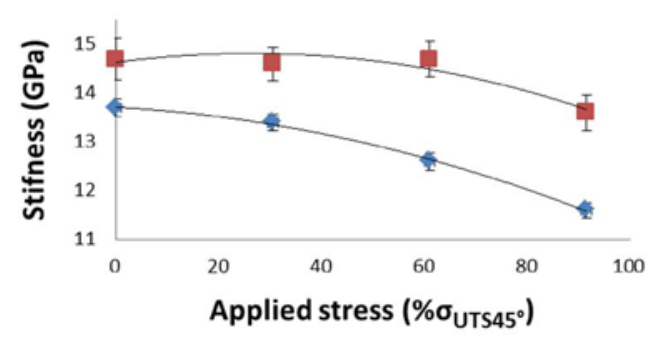

$\mathrm{C}_{12}$ and $\mathrm{C}_{44}$
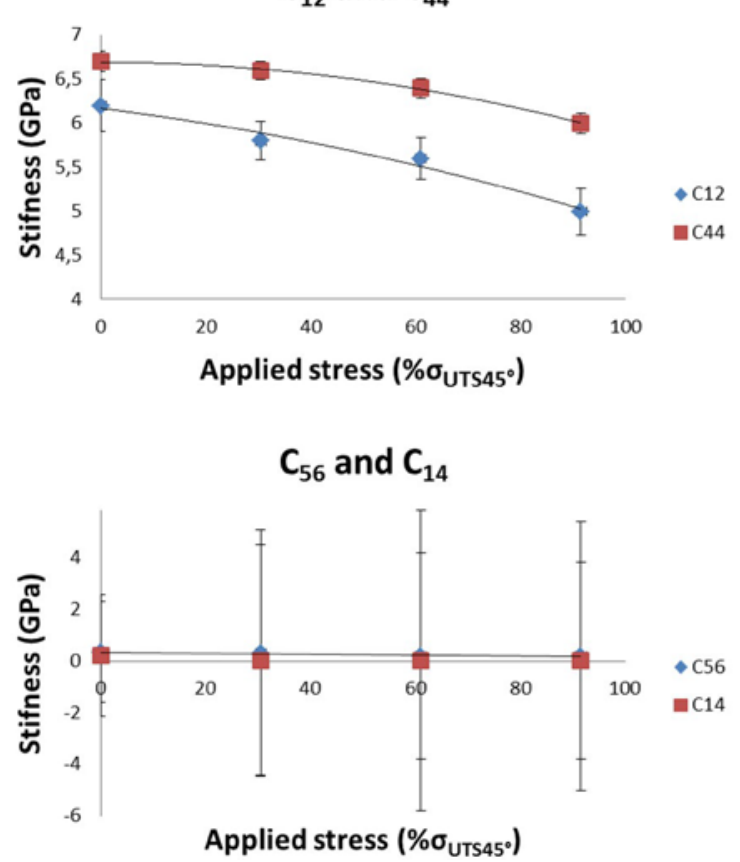

$\mathrm{C}_{33}$
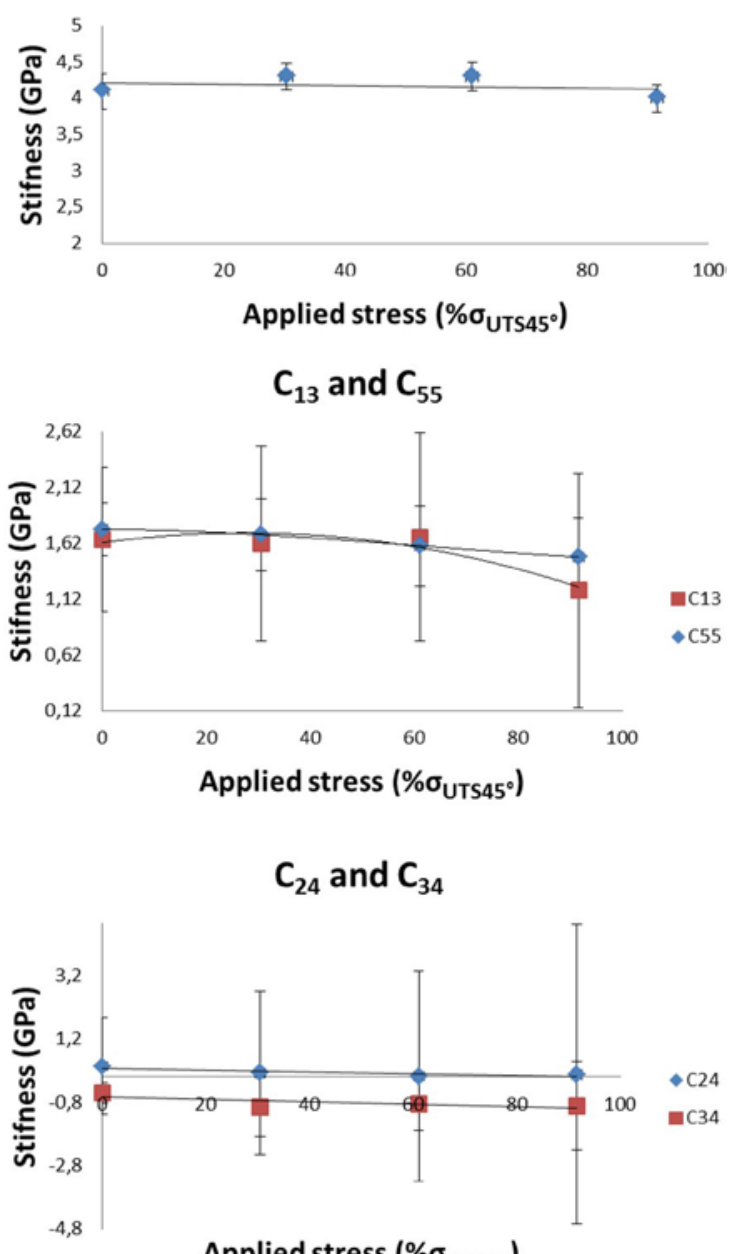

Fig. 21 Evolution of seven of the stiffness constants with the increase of the applied stress level for different $45^{\circ}$ configuration of sample with their respective confidence interval

compare the damage state between the different samples. The post processing time to obtain the stiffness constants can be long, so it is interesting to identify a method that can quickly estimate the damage state of the studied material by using the ultrasonic signal directly. In this study, a scalar variable as damage indicator is proposed that is applicable in the industry as a practical tool. Usually in the field of ultrasonic, the damage estimation is based on the amplitude attenuation, which is extracted from the raw ultrasonic results (transmitted time signals) presented in the previous section. However, it is not really efficient in the present case because it exhibits important oscillations when increasing the loading. Therefore, another damage indicator is necessarily required.

Two damage indicators are presented in this section. The first is the Frobenius norm of the computed stiffness and the second is based on the phase angle shift between wave signals propagated through a damaged and an undamaged sample.

\subsection{Frobenius Norm of the Stiffness Tensor Based Damage Indicator}

The Frobenius norm of a tensor is defined as follows:

$\left.N_{f}(C)=/ \frac{}{\operatorname{trace}(C * C}\right)$

With $\boldsymbol{C}$ : the stiffness tensor and $\boldsymbol{C}$ : its conjugate transpose.

Taking into account that a proper damage indicator should have a cumulative evolution with the increase of the damage state, the following damage indicator is adopted:

$D I_{1}=a b s\left(N_{f}(\boldsymbol{C})-N_{f 0}\left(C_{0}\right)\right.$

where $N_{f 0}$ is the Frobenius norm of an undamaged sample's stiffness matrix and $C_{0}$ is the undamaged sample's stiffness matrix. It is recalled that the Frobenius norm actually computes the norm of the eigenvector of the matrix $\mathbf{C}$. This is 

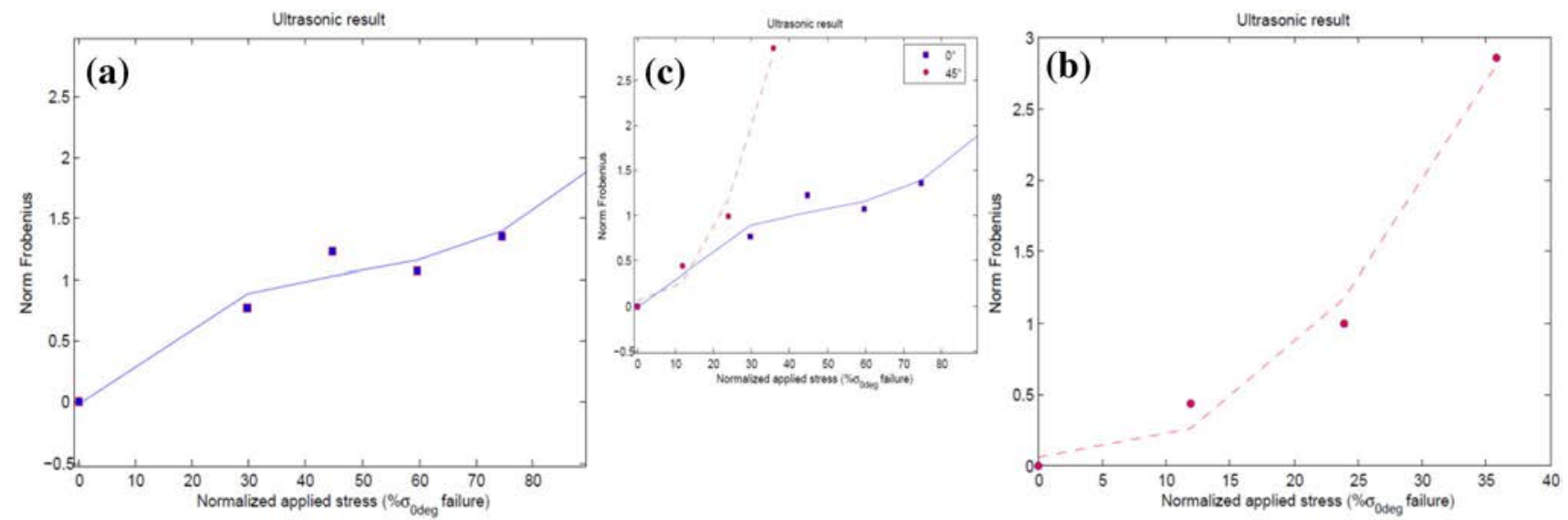

Fig. 22 Evolution of the Frobenius norm of the stiffness matrix for the two configurations of samples $\mathbf{a} 0^{\circ}$ and $\mathbf{b} 45^{\circ}$ function. In $\mathbf{c}$ data of both configurations are plotted for comparison purpose

more convenient for this study compared to the quadratic norm or the largest singular value that does not take into account all the components of the eigenvector.

The resulting evolution of the Frobenius norm is plotted, for the configuration $0^{\circ}$ and $45^{\circ}$, in the Fig. 22a, b respectively. The Fig. 22c with the two configurations is plotted for an easy comparison. A global increase of the indicator for both cases was clearly observed as expected. Furthermore, it was noticed that the indicator increases moderately faster for the $45^{\circ}$ than for the $0^{\circ}$ configuration. This aspect is consistent with the different response of the samples when submitted to tension, since the behavior is ductile for $45^{\circ}$ and brittle for $0^{\circ}$. The propagation of more cracks in the $45^{\circ}$ samples was observed by mCT as presented in Sect. 3. The indicator's value of the $45^{\circ}$ sample loaded at $91.6 \% \boldsymbol{\sigma}_{U T S 45^{\circ}}$ is actually even higher than the corresponding one for the $0^{\circ}$ sample loaded at $92.6 \% \boldsymbol{\sigma}_{U T S 0^{\circ}}$.

\subsection{Phase Shift Based Damage Indicator}

The global shape of the transmitted signal remains mostly unchanged whatever the damage severity at this frequency range as it can be observed in Fig. 23. The phase shift of the signal is therefore considered as a pertinent choice to quantify damage state evolution. The non-evolution of the global shape of the signal is induced by the choice of a frequency with which the composite sample is considered as homogenous. It is worth mentioning that the time shift corresponds

to change in phase or group velocity depending on the case when they are different from each other, as visible in Fig. 16. However, the damage indicator that is determined is not an extraction of that velocity but is used as is.

This shift is of course function of the wave propagation velocity change that was seen to be effective for quantifying damage, as shown in Sect. 4. In addition, by considering multiple incidence angles, an anisotropic investigation of damage
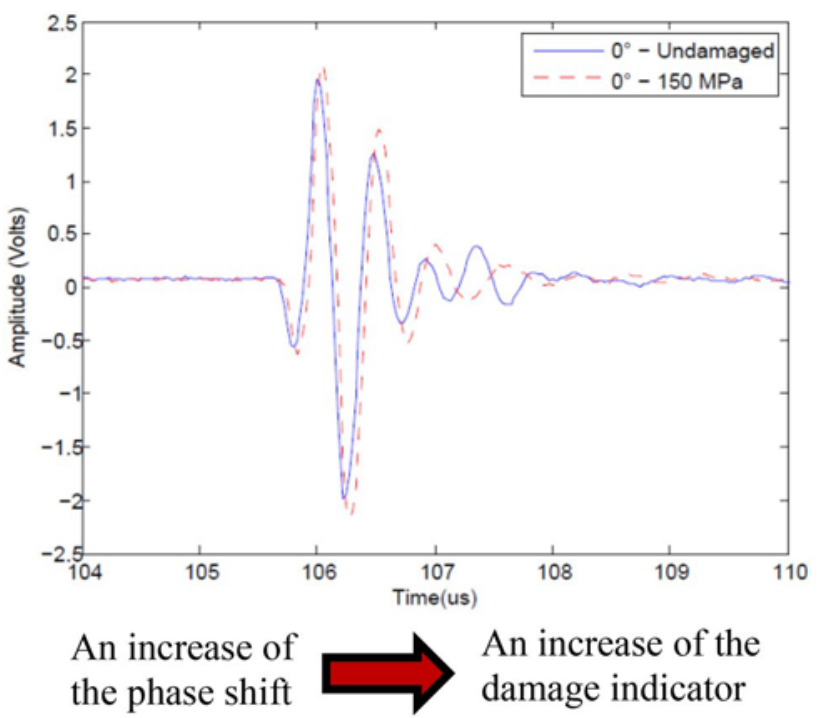

Fig. 23 Response of ultrasonic signals that propagates through the 1-3 plane, at 0 of incidence, of a 0 undamaged sample and loaded at a stress level of $150 \mathrm{MPa}$

is possible. This was demonstrated in Sect. 5, and is an important advantage of the proposed damage indicator. Therefore, as for the previous indicator, the average of all incidence angles of the phase shift was calculated. An increase of the phase shift of the signals induces an increase of the damage indicator. The phase shift indicator is calculated as follow:

$D I_{2}=\frac{1}{{ }_{n}}{ }_{1}^{*}{ }_{0}^{n_{\max }}$ abs $\stackrel{(}{p h}(n)-{ }^{-} p h 0(n)$,

$\left.p h(n)=\overline{s p}^{*} \quad{ }_{t} p h(t, n) \neq\right)$

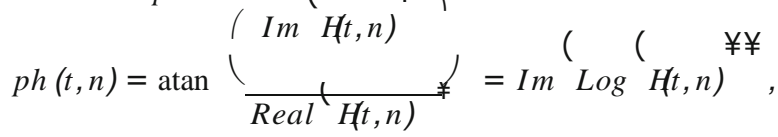



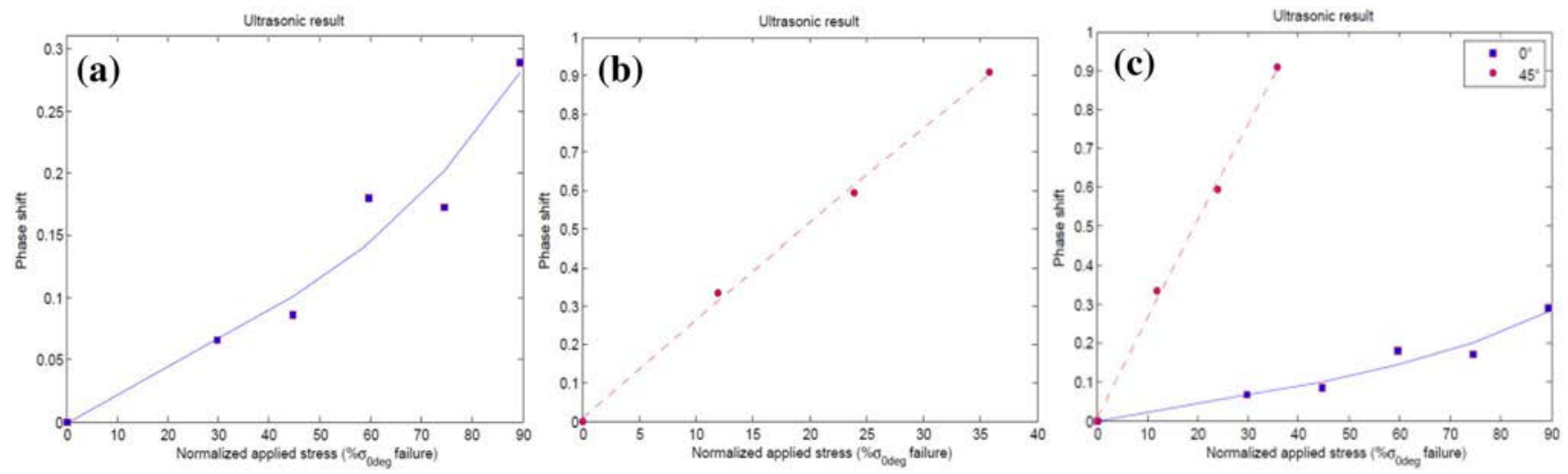

Fig. 24 Absolute phase angles evolution with increasing tensile stress to the sample for $\mathbf{a} 0^{\circ}$ and $\mathbf{b} 45^{\circ}$ configuration of sample. In $\mathbf{c}$ data of both configurations are plotted for comparison purpose

\section{Ultrasound based damage indicators}
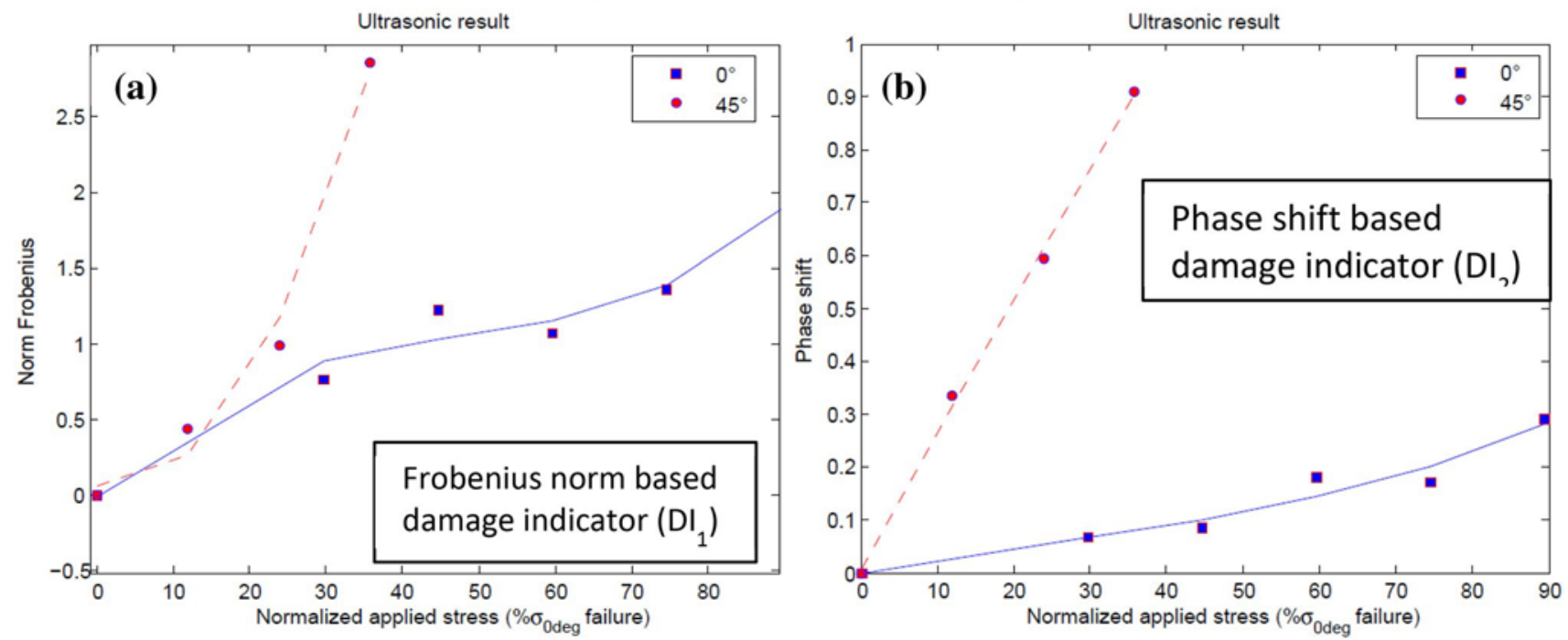

Fig. 25 Proposed ultrasonic damage indicators. a Evolution of Frobenius Norm and $\mathbf{b}$ Phase shift indicator. Those indicators a plotted for the sets of samples oriented at $0{ }^{\circ}$ and $45^{\circ}$ from the warp direction and function of the normalized applied stress level

with $n$ the considered incidence angle; sp the sampling points of the evaluated signal; $H(n)$ the Hilbert transform of the signal responsefor a given $\mathrm{n}$.

The evolution of this proposed damage indicator for the two samples configurations $0^{\circ}$ and $45^{\circ}$ is respectively plotted in Fig. 24a and in Fig. 24b. In the Fig. 24c, the evolution of the damage indicator is plotted for the two samples configurations for comparison purpose. The Fig. 24 points out that the damage measured, using the phase shift indicator, for the sample in the $45^{\circ}$ configuration loaded at stress level of $91.6 \% \boldsymbol{\sigma}_{U T S 45}{ }^{\circ}$ reach a level of 0.9 . This is clearly higher than the damage level of 0.3 measured on the sample in the $0^{\circ}$ configuration and loaded at a stress level of $92.6 \% \boldsymbol{\sigma}_{\boldsymbol{U}} \boldsymbol{T S 0 ^ { \circ }}{ }^{\circ}$. This was also observed with the first damage indicator based on the Frobenius norm depicted in Fig. 22. It must be emphasized that the proposed damage indicator is a relative estimation of the damage with respect to a reference state, which is generally the undamaged state. The experimental procedure and arrangements must be rigorously identical when performing the ultrasonic wave measurements both on the undamaged composite sample and on the damaged one. Indeed, issues with the alignment of the transducers or the measurement triggering could induce errors in the signals comparison and lead to inaccurate diagnosis.

The two proposed ultrasound based damage indicators (DI 1 and $\mathrm{DI}_{2}$ ) are respectively plotted in Fig. 25a, b. As illustrated in this figure, the evolution of the Frobenius norm for 

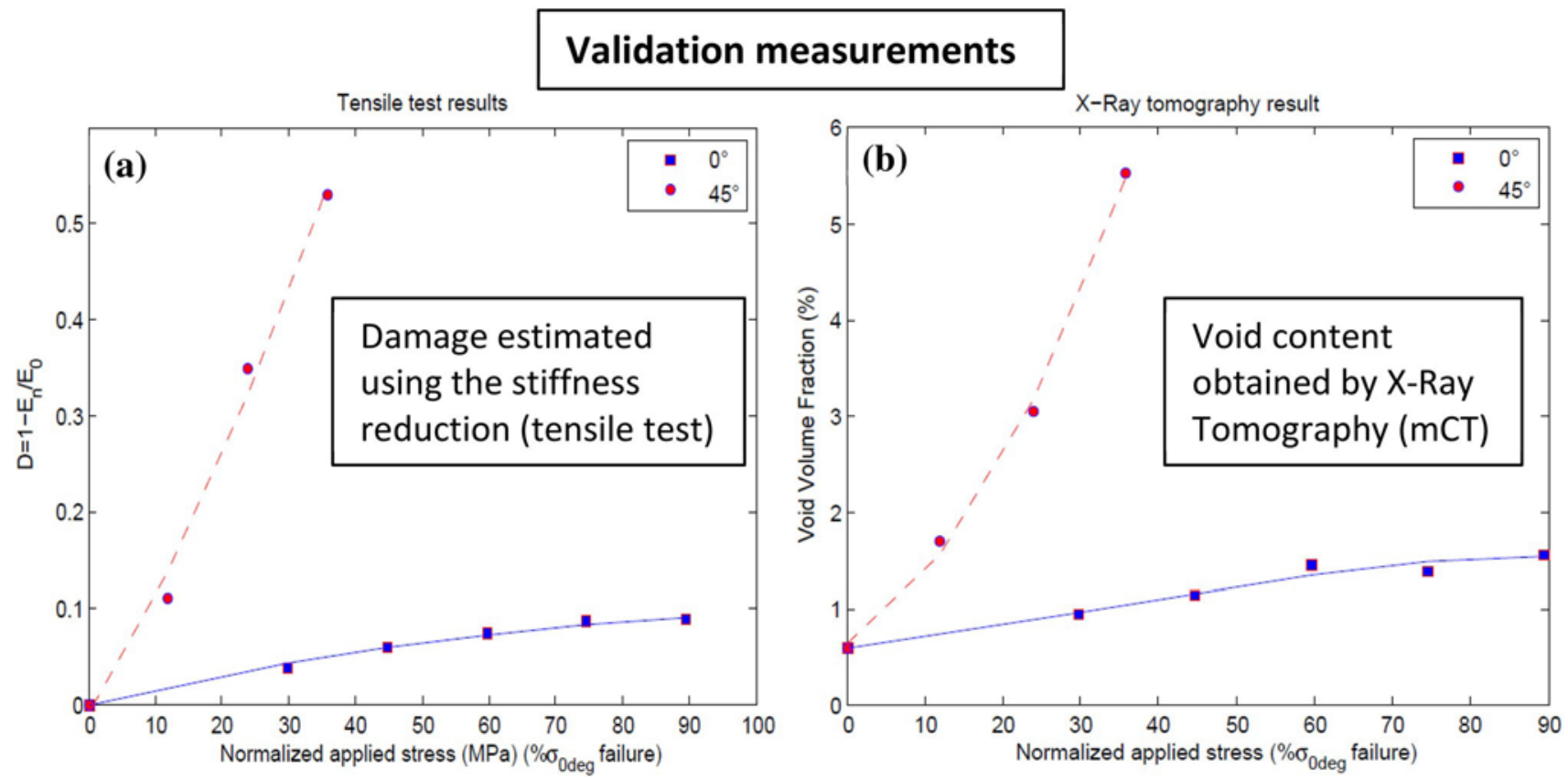

Fig. 26 Damage indicators used as validation tools. a Damage estimated on the elastic modulus reduction and $\mathbf{b}$ Void volume fraction. Those indicators a plotted for the sets of samples oriented at $0^{\circ}$ and $45^{\circ}$ from the warp direction and function of the normalized applied stress level

the two sets of samples is very close, until an applied stress ratio of $30 \% \boldsymbol{\sigma}_{U T S 0^{\circ}}{ }^{\circ}$. Beyond this ratio, the Frobenius norm for the $45^{\circ}$ samples has a faster evolution than that of the $0^{\circ}$ samples. For the phase shift based indicator, the difference between the two samples orientations is more pronounced.

For an applied stress ratio of $12 \% \boldsymbol{\sigma}_{U T S 0^{\circ}}$ on the $45^{\circ}$ samples the value of $\mathrm{DI}_{2}$ reach 0.32 which is close to the highest value reach for the $0{ }^{\circ}$ samples. Globally, the two new ultrasound based damage indicators reveal a higher increase of the damage state for the samples oriented at $45^{\circ}$ from the warp direction.

The estimation of damage based on the elastic modulus reduction determined in Sect. 2 as well as the void volume evolution from the X-ray mCT measurements presented in Sect. 3 are respectively plotted in Fig. 26a, b. This figure presents the experimental results used as validation for the new indicators. They indeed exhibit a similar damage evolution as function of the applied stress ratio with a higher increase for samples in the $45^{\circ}$ configurations. It must be noted that the kinetic growth of damage is better predicted by the proposed phase angle shift indicator when compared to those two validation criteria.

\section{Concluding Remarks}

The anisotropic evolution of damage in polymer based woven composite material is strongly affected by fiber orientation and loading direction. This leads to the appearance of various damage mechanisms that influence the structural integrity differently. The development of nondestructive evaluation techniques is therefore necessary to determine the possible degradation of composite components on-site in a very applicable fashion, in service. These techniques should, however simple, still be sensitive to different damage state evolution schemes.

The present study and results aimed at detecting and quantifying the anisotropic evolution of damage with ultrasonic techniques. More specifically polyamide 6.6/6 reinforced with $2 / 2$ twill weave glass fabric samples, preliminary damaged by stepwise increase interrupted tensile loading, were used. Two sample configurations were considered: (i) samples oriented at $0^{\circ}$ and (ii) at $45^{\circ}$ from the mold flow direction (corresponding to the warp direction). This choice was based on the knowledge of the different behavior between the two orientations, which is from brittle to ductile. The decrease of the elastic modulus was also measured for every considered stress level and used as a first validation result for the proposed damage indicators. A higher evolution of damage was observed for the samples oriented at $45^{\circ}$ from the warp fiber direction.

After highlighting the limitations of classical ultrasonic $\mathrm{C}$-scan imaging to detect early damage state, $\mathrm{X}$-ray mCT has been used to observe the different damage mechanisms such as matrix cracking, micro-buckling and fiber breakage. The void volume fraction was also measured on all considered samples. From the first experimental results, it was observed and confirmed that the largest damage mechanisms appear 
on samples in the $45^{\circ}$ configuration. Those samples exhibited also a higher increase of void volume fraction than the samples oriented at $0^{\circ}$ from the warp direction.

Measurements of the stiffness components on several samples previously damaged at different levels were also performed based on ultrasonic methods. A clear evolution of the stiffness components' values was observed even for the lowest damage state considered. Both studied samples configurations actually exhibit a response that differs from one another. However, it may be difficult to have evident information on the global damage state from the full stiffness matrix. It was proposed to consider scalar variables, obtained using results from the same ultrasonic method, as damage indicators. . It may be true that scalar variables in general lack extensiveness compared with higher dimensional vector or tensor variables, but if what they represent as information is functional as damage indicator then they can be used in the industry. The Frobenius norm of those stiffness matrixes was firstly used as a damage indicator. A damage indicator based on phase angle shift was also proposed to estimate the damage. The information delivered by those two damage indicators showed similarities with the results given by void volume fraction evolution and elastic modulus reduction. In other words, the samples oriented at $45^{\circ}$ from the warp direction exhibited a higher damage increase with increasing the loading level than the samples in the $0{ }^{\circ}$ configuration. However, the kinematic increase of damage of the two studied configurations of samples was more successfully evaluated by the phase angle shift damage indicator, if referring to the tensile tests and X-ray mCT results.

The presented ultrasonic method provides an appropriate approach to evaluate the global damage state of a composite material reinforced with a complex fabric. Now that the method is effective under laboratory condition on standard samples, the next step is to validate the method on more complex automotive parts. The proposed method requires adaptations for practical applications. It must be robust in order to provide good repeatability of the measurement to avoid measurement errors that could alter the quality of the damage evaluation, such as wrong ultrasonic transducers' alignment and measurement triggering. An investigation of the method's sensitivity with air-coupled transducer could also be considered. Indeed, for more practical applications of the damage evaluation procedure on assembly lines, immersion of samples in water should be avoided to improve the method's applicability.

Acknowledgements Thepresent work was fundedby PSA Group and made in the framework of the OpenLab Materials and Processes. This OpenLab involves PSA Group, The Arts et Metiers ParisTech and Georgia Tech Lorraine.

\section{References}

1. Volgers, P., Kuhlmann, H., Zhang, Z.: New constitutive model for woven thermoplastic composite materials . In: 2015 SIMULIA Community Conference, pp. 1-13 (2015)

2. Artero-Guerrero, J.A., Pernas-Sánchez, J., López-Puente, J., Varas, D.: Experimental study of the impactor mass effect on the low velocity impact of carbon/epoxy woven laminates. Compos. Struct. 133, 774-781 (2015). https://doi.org/10.1016/j.compstruct.2015. 08.027

3. Malpot, A., Touchard, F., Bergamo, S.: Effect of relative humidity on mechanical properties of a woven thermoplastic composite for automotive application. Polym. Test 48, 160-168 (2015). https:// doi.org/10.1016/j.polymertesting.2015.10.010

4. Atas, C., Sayman, O.: An overall view on impact response of woven fabric composite plates. Compos. Struct. 82, 336-345 (2008). https://doi.org/10.1016/j.compstruct.2007.01.014

5. Golzar, M., Poorzeinolabedin, M.: Prototype fabrication of a composite automobile body based on integrated structure. Int. J. Adv. Manuf. Technol. 49, 1037-1045 (2010). https://doi.org/10.1007/ s00170-009-2452-6

6. Markham, M.F.: Measurement of the elastic constants of fibre composites by ultrasonics. Composites 1, 145-149 (1969)

7. Marguères, P., Meraghni, F., Benzeggagh, M.L.: Comparison of stiffness measurements and damage investigation techniques for a fatigued and post-impact fatigued GFRP composite obtained by RTM process. Compos. Part A Appl. Sci. Manuf. 31, 151-163 (2000)

8. Marguères, P., Meraghni, F.: Damage induced anisotropy and stiffness reduction evaluation in composite materials using ultrasonic wave transmission. Compos. Part A Appl. Sci. Manuf. 45, 134-144 (2013)

9. Hufenbach, W., Ritschel, T., Böhm, R., Langkamp, A.: Ultrasonic determination of anisotropic damage in fibre and textile reinforced composite materials. In: Conference on Damage in Composite Materials (2006)

10. Baste, S., Aristégui, C.: Induced anisotropy and crack systems orientations of a ceramic matrix composite under off-principal axis loading. Mech. Mater. 29, 19-41 (1998). https://doi.org/10.1016/ S0167-6636(98)00003-9

11. Ong, W.H., Rajic, N., Chiu, W.K., Rosalie, C.: Determination of the elastic properties of woven composite panels for Lamb wave studies. Compos. Struct. 141, 24-31 (2016). https://doi.org/10.1016/j. compstruct.2015.12.017

12. Moreno, E., Galarza, N., Rubio, B., Otero, J.A.: Phase velocity method for guided wave measurements in composite plates. Phys. Procedia 63, 54-60 (2015). https://doi.org/10.1016/j.phpro.2015. 03.009

13. Satyanarayan, L., Vander Weide, J.M., Declercq, N.F.: Ultrasonic polar scan imaging of damaged fiber reinforced composites. Mater. Eval. 68, 733-739 (2010)

14. Kersemans, M., Martens, A., Van Den Abeele, K., et al.: Detection and localization of delaminations in thin carbon fiber reinforced composites with the ultrasonic polar scan. J. Nondestruct. Eval. 33, 522-534 (2014). https://doi.org/10.1007/s10921-014-0249-5

15. Karayaka, M., Kurath, P.: Deformation and failure behavior of woven composite laminates. J. Eng. Mater. Techol. 116, 222-232 (1994)

16. Pandita, S.D., Huysmans, G., Wevers, M., Verpoest, I.: Tensile fatigue behaviour of glass plain-weave fabric composites in on- and off-axis directions. Compos. Part A Appl. Sci. Manuf. 32, 15331539(2001). https://doi.org/10.1016/S1359-835X(01)00053-7

17. Ladeveze, P., Le, Dantec E.: Damage modelling of the elementary ply for laminated composites. Compos. Sci. Technol. 43, 257-267 (1992) 
18. Eckel, S., Meraghni, F., Pomarède, P., Declercq, N.F.: Investigation of damage in composites using nondestructive nonlinear acoustic spectroscopy. Exp. Mech. 57, 207-217 (2017). https://doi.org/10. 1007/s11340-016-0222-6

19. Meo, M., Polimeno, U., Zumpano, G.: Detecting damage in composite material using nonlinear elastic wave spectroscopy methods. Appl. Compos. Mater. 15, 115-126 (2008). https://doi.org/10. 1007/s10443-008-9061-7

20. Ren, G., Kim, J., Jhang, K.-Y.: Relationship between second- and third-order acoustic nonlinear parameters in relative measurement. Ultrasonics 56, 539-544 (2015). https://doi.org/10.1016/j.ultras. 2014.10.009

21. Shah, A.A., Ribakov, Y.: Non-linear ultrasonic evaluation of damaged concrete based on higher order harmonic generation. Mater. Des. 30, 4095-4102 (2009). https://doi.org/10.1016/j. matdes.2009.05.009

22. Madi, K.: Influence de la morphologie tridimensionnelle des phases sur le comportement mécanique de réfractaires électrofondus. Ecole Nationale Supérieure des Mines de Paris (2006)

23. Vieille, B., Taleb, L.: About the influence of temperature and matrix ductility on the behavior of carbon woven-ply PPS or epoxy laminates: Notched and unnotched laminates. Compos. Sci. Technol. 71,998-1007(2011). https://doi.org/10.1016/j.compscitech.2011. 03.006

24. Madra, A., El, Hajj N., Benzeggagh, M.: X-ray microtomography applications for quantitative and qualitative analysis of porosity in woven glass fiber reinforced thermoplastic. Compos. Sci. Technol. 95, 50-58 (2014). https://doi.org/10.1016/j.compscitech.2014.02. 009
25. Williams, J.J., Chapman, N.C., Jakkali, V.: Characterization of damage evolution in sic particle reinforced $\mathrm{Al}$ alloy matrix composites by in-situ X-ray synchrotron tomography. Metall. Mater. Trans. A Phys. Metall. Mater. Sci. 42, 2999-3005 (2011). https:// doi.org/10.1007/s11661-011-0718-8

26. Dalmaz, A., Ducret, D., El, Guerjouma R., et al.: Elastic moduli of a 2.5D C f/SiC composite?: experimental and theoretical estimates. Compos. Sci. Technol. 60, 913-925 (2000)

27. Karim, M.R., Mal, A.K.: Determination of the elastic constants of composites through the inversion of Leaky Lamb Waves data. Rev. Prog. Quant. Nondestruct. Eval. 9, 1411-1418 (1990)

28. Kim, Y.H., Song, S., Kwon, S.: Measurement of phase velocity dispersion curves and group velocities in a plate using leaky Lamb waves. In: Conference \& Exhibition on Non-Destructive Evaluation. ISNT (2002)

29. Nayfeh, A.H.: Wave Propagation in Layered Anisotropic Media. Elsevier, New York (1995)

30. Lomov, S.V, Ivanov, D.S., Verpoest, I. et al.: Predictive analyses and experimental validations of effective elastic properties of $2 \mathrm{D}$ and 3D woven composites. In: 13th European Conference of Composite Materials (2008)

31. Audoin, B., Baste, S., Castagnede, B.: Estimation de l’intervalle de confiance des constantes d'élasicité identidiées à partir des vitesses de propagation ultrasonore. C. R. Acad. Sci. 312, 676-686 (1991) 